\title{
(2) OPEN ACCESS \\ Transjugular intrahepatic portosystemic stent-shunt in the management of portal hypertension
}

\author{
Dhiraj Tripathi (D) , ${ }^{1,2,3}$ Adrian J Stanley (D) , ${ }^{4}$ Peter C Hayes (D) , ${ }^{5}$ Simon Travis, ${ }^{6}$ \\ Matthew J Armstrong (D) , 1,2,3 Emmanuel A Tsochatzis (D) ,' Ian A Rowe (D) , \\ Nicholas Roslund ${ }^{9}$ Hamish Ireland (D) , ${ }^{10}$ Mandy Lomax, ${ }^{11}$ Joanne A Leithead, ${ }^{12}$ \\ Homoyon Mehrzad, ${ }^{13}$ Richard J Aspinall (D) , ${ }^{14}$ Joanne McDonagh, ${ }^{1}$ David Patch ${ }^{7}$
}

For numbered affiliations see end of article.

Correspondence to Dr Dhiraj Tripathi, Liver Unit, University Hospitals Birmingham NHS Foundation Trust, Birmingham B15 2TH, UK ; d.tripathi@bham.ac.uk

Received 2 November 2019 Revised 20 January 2020 Accepted 22 January 2020 Published Online First 29 February 2020
Check for updates

(C) Author(s) (or their employer(s)) 2020. Re-use permitted under CC BY-NC. No commercial re-use. See rights and permissions. Published by BMJ.

To cite: Tripathi $\mathrm{D}$ Stanley AJ, Hayes PC, et al. Gut 2020:69:1173-1192.

\section{ABSTRACT}

These guidelines on transjugular intrahepatic portosystemic stent-shunt (TIPSS) in the management of portal hypertension have been commissioned by the Clinical Services and Standards Committee (CSSC) of the British Society of Gastroenterology (BSG) under the auspices of the Liver Section of the BSG. The guidelines are new and have been produced in collaboration with the British Society of Interventional Radiology (BSIR) and British Association of the Study of the Liver (BASL). The guidelines development group comprises elected members of the BSG Liver Section, representation from BASL, a nursing representative and two patient representatives. The quality of evidence and grading of recommendations was appraised using the GRADE system. These guidelines are aimed at healthcare professionals considering referring a patient for a TIPSS. They comprise the following subheadings: indications; patient selection; procedural details; complications; and research agenda. They are not designed to address: the management of the underlying liver disease; the role of TIPSS in children; or complex technical and procedural aspects of TIPSS.

EXECUTIVE SUMMARY OF RECOMMENDATIONS Recommendations: TIPSS for variceal bleeding

- In patients who have gastro-oesophageal variceal bleeding refractory to endoscopic and drug therapy as defined by Baveno 6 critera, ${ }^{32}$ transjugular intrahepatic portosystemic stentshunt (TIPSS) is recommended (strong recommendation, moderate-quality evidence). Salvage TIPSS is not recommended where the Child-Pugh score is $>13$ (strong recommendation, low quality of evidence).

- In patients who have Child's C disease (C1013) or MELD $\geq 19$, and bleeding from oesophageal varices or GOV1 and GOV2 gastric varices and are haemodynamically stable, early or pre-emptive TIPSS should be considered within 72 hours of a variceal bleed where local resources allow (weak recommendation, moderate quality of evidence). However, large multi-centre randomised controlled trials (RCTs) are necessary to determine whether patients with Child's B disease and active bleeding or with MELD 12-18 benefit from early pre-emptive TIPSS.
- In secondary prevention of oesophageal variceal bleeding, TIPSS can be considered where patients rebleed despite combination of $\mathrm{VBL}+\mathrm{NSBB}$ taking into account the severity of rebleeding and other complications of portal hypertension, with careful patient selection to minimise hepatic encephalopathy (weak recommendation, moderate-quality evidence). Further large controlled trials are required to investigate the role of TIPSS as first-line therapy in secondary prevention (strong recommendation, low quality of evidence).

- In secondary prevention of gastric variceal bleeding, TIPSS \pm embolisation is recommended where patients rebleed despite endoscopic injection therapy (strong recommendation, moderate-quality evidence). TIPSS \pm embolisation can also be considered in selected patients with large or multiple gastric varices as first-line therapy in secondary prevention (weak recommendation, moderate-quality evidence).

- In patients with bleeding from ectopic varices refractory to local and pharmacological therapies, TIPSS usually with embolisation is suggested (weak recommendation, low-quality evidence).

- In patients with bleeding from portal hypertensive gastropathy (PHG) refractory to NSBB and iron therapy, TIPSS may be considered (weak recommendation, low-quality evidence).

\section{Recommendations: TIPSS for ascites}

- In patients who are eligible for liver transplantation, TIPSS for ascites should only be undertaken after discussion with the regional transplant centre (strong recommendation, very low quality evidence).

- In selected patients with refractory or recurrent ascites, we recommend insertion of TIPSS provided there are no contraindications to the procedure (strong recommendation, high quality evidence).

- In addition to the standard TIPSS contraindications, patients who may not benefit from TIPSS for ascites include those with bilirubin $>50 \mu \mathrm{m} / \mathrm{L}$ and platelets $<75 \times 10^{9}$, pre-existing encephalopathy, active infection, severe cardiac failure or severe pulmonary hypertension (strong recommendation, moderate quality evidence). 


\section{Recommendation: TIPSS for hydrothorax}

- Selected patients with refractory hepatic hydrothorax may be considered for TIPSS insertion. (strong recommendation, moderate-quality evidence).

\section{Recommendation: TIPSS for hepatorenal syndrome (HRS)}

- Although, renal function has been observed to improve following TIPSS, TIPSS for HRS (type 1 and type 2) remains experimental (weak recommendation, very low level of evidence).

\section{Recommendations: TIPSS for Budd-Chiari syndrome}

- It is recommended that all patients with Budd-Chiari syndrome (BCS) are managed in centres of high expertise which are either transplant centres or have formal links with a liver transplant centre (strong recommendation, very lowquality evidence).

- TIPSS is recommended where patients fail to respond to medical therapy with anticoagulation or hepatic vein interventions (strong recommendation, moderate- quality evidence). TIPSS can be considered where hepatic vein interventions is not technically feasible (weak recommendation, low-quality evidence).

- Patients with poor prognostic scores (see text), or those who do not respond to anticoagulation and radiological therapies, have a poor prognosis and should be considered for liver transplant assessment (strong recommendation, moderate-quality evidence).

\section{Recommendation: prophylactic TIPSS}

- There is insufficient data to recommend TIPSS prior to nonhepatic surgery, although in compensated cirrhotic patients undergoing curative surgery for cancer there may be a role (weak recommendation, low-quality evidence). Further research is recommended, with the focus on careful patient selection.

\section{Recommendation: TIPSS for idiopathic non-cirrhotic portal hypertension}

- The indications for TIPSS in idiopathic non-cirrhotic portal hypertension (INCPH) should be similar to cirrhosis, and covered stents are preferred. The selection criteria should also be similar to cirrhosis with particular attention to risk factors for hepatic encephalopathy (weak recommendation, low-quality evidence).

\section{Recommendations: TIPSS in portal vein thrombosis}

- Portal vein thrombosis (PVT) should not be considered an absolute contraindication to TIPSS placement, although the presence of cavernoma is associated with a significantly high failure rate (strong recommendation, high-quality evidence).

- Patients with acute PVT should be discussed with experienced units (weak recommendation, very low-quality evidence).

- Cirrhotic patients with PVT and variceal bleeding should be discussed with experienced units (weak recommendation, low-quality evidence).

\section{Recommendations: TIPSS and hepatic encephalopathy}

- TIPSS may worsen or precipitate encephalopathy. Patients undergoing elective TIPSS should be screened for covert and overt encephalopathy (strong recommendation, high-quality evidence).
- Screening should ideally be at least two of the following: psychometric hepatic encephalopathy score (PHES) testing, Stroop testing, Critical Flicker Frequency and Spectral Enhanced or quantative EEG (strong recommendation, moderate-quality evidence).

- The presence of covert hepatic encephalopathy is a relative contraindication to elective TIPSS (weak recommendation, low-quality evidence).

- Although age $>65$ is not an absolute contraindication, it might increase the risk of encephalopathy and should be taken into account when deciding the eligibility for elective TIPSS (weak recommendation, low-quality evidence).

- Patients who develop encephalopathy following a TIPSS should be managed according to standard guidelines, but if encephalopathy continues, consideration should be given to shunt reduction, embolisation or occlusion (weak recommendation, low level of evidence).

\section{Recommendations: cardiac assessments}

- A cardiac history, examination, 12-lead ECG and N-Terminal pro-B-type natriuretic peptide (NT-proBNP) should be undertaken in all patients undergoing elective TIPSS insertion (strong recommendation, moderate-quality evidence). Further cardiac evaluation (echocardiogram +/-cardiology consultation) should be undertaken before elective TIPSS if any of these are abnormal (strong recommendation, moderate-quality evidence).

- Elective TIPSS is not recommended in patients with severe left ventricular dysfunction or severe pulmonary hypertension (strong recommendation, moderate- quality evidence).

- Echocardiogram in acute variceal haemorrhage may be inaccurate and should not delay an emergency, potential lifesaving TIPSS insertion (strong recommendation, low-quality evidence).

\section{Recommendation: nutritional assessment}

- Patients referred for elective TIPSS insertion should undergo a detailed nutritional and functional assessment (weak recommendation, low-level evidence).

\section{Recommendations: renal function}

- In patients with significant intrinsic renal disease (stage 4/5), elective TIPSS is not recommended (strong recommendation, low-quality evidence).

- TIPSS can be considered in patients presenting acutely with variceal bleeding and renal dysfunction (weak recommendation, very low-level evidence).

\section{Recommendations: preparation for TIPSS}

- All patients considered for elective TIPSS should be discussed in a multidisciplinary team, and be reviewed by both hepatology and interventional radiology in the clinical setting as part of the work-up (strong recommendation, very low level of evidence).

- Cross-sectional imaging is recommended prior to TIPSS where possible (strong recommendation, very low level of evidence).

- Informed consent should follow established principles (strong recommendation, high level of evidence).

- General anaesthetic or deep sedation using propofol is recommended for all procedures (strong recommendation, very low level of evidence). 
- Routine prophylactic antibiotics are not recommended with the exception of TIPSS for variceal bleeding, complex procedures or where there is previous biliary instrumentation (strong recommendation, very low level of evidence).

- The decision to correct any coagulopathy should be based on thromboelastography since INR is often unreliable in liver disease (strong recommendation, moderate level of evidence). Platelet transfusion can be considered if platelet count $<50 \times 10^{5} / \mathrm{L}$ (weak recommendation, very low level of evidence).

\section{Recommendations: TIPSS procedure}

- All TIPSS should be performed using PTFE-covered stents as they are associated with better patency rates than bare stents (strong recommendation, high level of evidence).

- The portal pressure gradient should be measured as that between the portal pressure and IVC, and measured pre- and post-stent deployment (strong recommendation, moderate level of evidence)

- The portal pressure gradient should be reduced to $<12 \mathrm{mmHg}$ or by $>=20 \%$ of baseline in the case of variceal bleeding (strong recommendation, high level of evidence). For other indications, further reductions in the portal pressure gradient needs to balance efficacy with risk of hepatic encephalopathy, and should be individualised (weak recommendation, low level of evidence).

- The role of embolisation with TIPSS is not clear and decisions should be individualised and based on cross-sectional imaging and portography showing large varices when portal pressure reduction alone may not be sufficient (weak recommendation, low level of evidence).

- A Doppler ultrasound is recommended a week after TIPSS implantation in patients with prothrombotic conditions, and in other patients where TIPSS dysfunction is suspected (strong recommendation, low level of evidence). Doppler ultrasound is recommended at 6-12 monthly intervals or 6-monthly in patients undergoing HCC surveillance (weak recommendation, low level of evidence).

- Patients with prothrombotic conditions such as BCS require follow-up with Doppler ultrasound with careful consideration for TIPSS venography as determined by the interventional radiologist. There is no indication for routine venography in other patients (strong recommendation, low level of evidence).

\section{Recommendations: service delivery and development}

- Units offering a TIPSS service should be performing a minimum of 10 cases per annum (strong recommendation, moderate quality of evidence).

- It is recommended that centres offering complex TIPSS (thrombosed hepatic or portal veins or in transplant recipients) should perform at least 20 cases per annum (strong recommendation, moderate quality of evidence).

- Patients being referred for emergency TIPSS should be prioritised for transfer (strong recommendation, low quality of evidence).

\section{Research recommendations}

- The role of early or pre-emptive TIPSS in acute variceal bleeding in view of the conflicting evidence and uncertainly about patient selection. Large multi-centre RCTs would be the gold standard.
- The role of TIPSS as first-line therapy in secondary prevention against variceal rebleeding.

- A national registry or database to help inform us about the results in a variety of indications and evaluate current service provision.

- Nutrition in patients undergoing TIPSS. Patients' nutrition can significantly improve following TIPSS for ascites but cachexia may be associated with more encephalopathy.

- TIPSS in the setting of chronic renal impairment and hepatorenal syndrome.

- Cardiac evaluation prior to TIPSS due to the limitations of the present methods. The role of NT-proBNP is not clear.

- Haemodynamic goals following TIPSS. Further study around the ideal reduction of portal pressure gradient both for variceal haemorrhage and the treatment of refractory ascites.

- The role of TIPSS in hepatic hydrothorax, and further study comparing TIPSS with standard of care is recommended.

- The role of prophylactic TIPSS prior to major non-hepatic surgery due to a lack of good-quality data on whether it improves outcome.

- Role of TIPSS in patients with ectopic varices to allow access to the portal system as well as reducing portal pressure.

\section{PATIENT SUMMARY}

This guideline has been produced under the auspices of the British Society of Gastroenterology (BSG) with endorsements from the British Association for the Study of the Liver (BASL) and British Society of Interventional Radiology (BSIR). It is aimed at teams of health professionals who refer patients to specialists for a TIPSS. This patient summary aims to summarise the key recommendations.

TIPSS is a non-surgical treatment for patients with liver disease and higher than normal pressures in the liver and surrounding blood vessels (known as portal hypertension), in particular the portal vein and hepatic veins. It involves a specialist (doctor) known as an interventional radiologist or hepatologist placing a bespoke metal tube (stent) inside the liver by inserting a wire through the jugular vein in the neck, then threading and guiding it (using X-ray) through the liver. The procedure is normally done under general anaesthetic or deep sedation, and takes approximately $90-120 \mathrm{~min}$ in uncomplicated cases. In the UK there are more than 35 hospitals that offer this procedure.

The main reasons ("indications") for performing a TIPSS are to treat bleeding from swollen veins in the gullet called varices (potentially an emergency) and excessive fluid build-up in the abdomen or stomach known as ascites. Other rarer indications involve diseases affecting the blood vessels leading out of (Budd Chiari syndrome) or into the liver (portal vein thrombosis).

The main complications of the procedure include bleeding, infection, heart failure, liver failure, kidney failure, fever, damage to blood vessels and bile ducts, and occur in less than 5\% of patients. Long-term complications such as hepatic encephalopathy (HE) affects one-third of patients. HE is a condition where the liver is not able to get rid of unwanted toxic chemicals such as ammonia (produced in the gut). Patients can become confused, drowsy or may fall into a coma or worse. In most cases HE responds positively to simple measures and medical therapy, but in a few patients it may be necessary to block off the TIPSS. It is very important that the patient is made fully aware of all these complications where possible.

To minimise the risk of complications, the following preparation/preparatory work is recommended:

a. Specialised scans to look at the liver and surrounding vessels. 
b. Liver and kidney function tests.

c. Tests of the blood's ability to clot.

d. Heart function tests.

e. A nutrition/dietary assessment.

f. Tests to judge the risk of a patient developing HE after the TIPSS procedure.

It is also possible to modify the procedure to reduce the risks of developing HE following TIPSS by, for instance, reducing the diameter of stent.

We recommend TIPSS (where there is good evidence to support its use) is performed in the following clinical situations:

a. Acute variceal bleeding unresponsive to other treatments such as endoscopy (camera examination of the gullet) with banding of varices and drug therapy (so-called standard of care). Patients who have very severe liver disease are unlikely to benefit since they will not tolerate the physical insult of a TIPSS procedure.

b. In a non-emergency situation to prevent further re-bleeding from varices where patients have bled again despite standard of care endoscopic and medical therapies.

c. In selected patients to prevent the build-up of fluid in the stomach (ascites) or lung (hydrothorax) where there is recurrent fluid build-up despite other treatments which includes insertion of a drain or use of water tablets. Although TIPSS is effective in reducing fluid build-up, there is no clear evidence of better survival and impact on quality of life is not clear.

d. To treat selected patients with BCS in specialist hospitals which also offer liver transplantation.

e. To treat portal vein thrombosis in selected patients in specialist hospitals performing a large number of TIPSS.

The role of TIPSS in the following clinical situations is not clear:

a. To prevent variceal rebleeding in selected patients at the time of first presenting with an acute bleeding episode after satisfactory stabilisation with standard of care. This is also known as "early" or "pre-emptive" where TIPSS is performed within 72 hours of an acute variceal bleed in a stable patient who has stopped bleeding. There is conflicting data on whether it is effective, and which patients stand to benefit from this option.

b. In patients with long-standing kidney disease.

c. In a very rare condition called idiopathic non-cirrhotic portal hypertension where there is disease in the small blood vessels in the liver.

d. TIPSS as a preventative therapy in patients with portal hypertension being considered for surgery outside of the liver such as operations for bowel cancer.

\section{INTRODUCTION}

This document is the first such guideline produced by the BSG in collaboration with BASL and BSIR. There have been a number of recent advances, in the absence of an up-to-date UK-based guidance on TIPSS aimed at referring teams. The key aim of this guidance is to promote dialogue between referring teams and specialists at regional TIPSS centres. Along the referral pathway, members of the multidisciplinary team comprising gastroenterologists, hepatologists and interventional radiologists play equally important roles in decisions relating to clinical indications for TIPSS, patient selection and procedural aspects of TIPSS. The latest evidence would suggest that TIPSS has an increasing role in the management of acute variceal bleeding and ascites. However, recent publications report on major challenges with regards to available resources and knowledge of referring teams in implementing any changes in practice suggested by the evidence, particularly with regards to acute variceal bleeding. ${ }^{1}$ There is increasing importance of careful patient selection, and we believe that this requires particular attention in light of emerging data. We are also aware of rarer indications for TIPSS, which may have more of a place in routine practice. ${ }^{2-4}$ Unless stated otherwise, all sections are with reference to covered TIPSS.

\section{GUIDELINE DEVELOPMENT}

These guidelines were drafted following discussions within the liver section of the BSG and acceptance by the proposal by the CSSC. The GDG comprised clinicians from hepatology, gastroenterology and interventional radiology with nursing and patient representation. There followed division of sections to be researched by designated authors as agreed by the GDG, and an exhaustive literature review. There was reference to previously published practice guidelines and positions statements, and guideline quality was assessed using the AGREE tool.

A preliminary guideline document was drafted by the authors following discussion and where necessary voting by members of the GDG. The draft guidelines were submitted for review by CSSC, then BSG council members. The guidelines were then reviewed by the BSIR and BASL. Finally, full peer review was undertaken by reviewers selected by the editorial board of Gut.

\section{ASSESSING THE QUALITY OF GUIDELINES: THE AGREE II INSTRUMENT}

The AGREE II instrument is an accepted method for appraising clinical guidelines. ${ }^{5}$ Six domains are listed:

\section{Scope and purpose}

The guidelines are intended for use by clinicians and other healthcare professionals managing patients with portal hypertensive complications of liver disease who are being considered for a TIPSS. The last international guidance on TIPSS was published by the American Association for the Study of Liver Diseases (AASLD) in 2009. Other guidelines exist incorporating some advice on the use of TIPSS, ${ }^{6}$ but a dedicated guideline focusing on referral pathways for TIPSS has not been published recently. Important developments are covered in depth due to the potential impact on clinical practice. The guidelines are primarily aimed at the management of adult patients

\section{Guideline development group membership and stakeholder involvement}

Membership of the group includes gastroenterologists, hepatologists and interventional radiologists with nursing and patient representation. The guideline has been reviewed and ratified by the BSIR and BASL.

\section{Rigour of development}

The published literature has been searched using Pubmed, Medline, Web of Knowledge and the Cochrane database between April 2018 and October 2019. The GDG met through a series of teleconferences and meetings in that time.

In accordance with the BSG advice on production of guidelines, the GDG applied the GRADE (Grading of Recommendations, Assessment, Development and Evaluations) system. Strength of recommendation was strong, or weak. ${ }^{7}$ Where the recommendation was unanimous a 'strong' recommendation was used, and where the decision was by majority and the recommendation was moderate or weak, 'we suggest' was used. 


\begin{tabular}{|c|c|}
\hline Certainty & Interpretation \\
\hline Very low & The true effect is probably markedly different from the estimated effect \\
\hline Low & The true effect might be markedly different from the estimated effect \\
\hline Moderate & $\begin{array}{l}\text { The authors believe that the true effect is probably close to the } \\
\text { estimated effect }\end{array}$ \\
\hline High & $\begin{array}{l}\text { The authors have a lot of confidence that the true effect is similar to } \\
\text { the estimated effect }\end{array}$ \\
\hline
\end{tabular}

Our grading of evidence was based on four level of evidence and the strength of our recommendation (strong, moderate or weak). (table 1)

Areas of disagreement about the recommendation grade were subjected to discussion and, if necessary, voting by members of the guidelines group. Where possible, the health benefits, side effects and risks of recommendations have been discussed. The guidelines will be subject to peer review after submission for consideration of publication in Gut.

\section{Clarity and presentation}

Recommendations are intended to be specific to particular situations and patient groups: where necessary, different options are listed. Key recommendations are linked to discussion threads on a discussion forum hosted on the BSG website.

\section{Applicability}

Where necessary, we have discussed organisational changes that may be needed in order to apply recommendations. We have attempted to identify key criteria for monitoring and audit purposes.

\section{Editorial independence and conflict of interest}

Guideline group members have declared any conflicts of interest.

\section{HISTORY OF TIPSS}

The idea of TIPSS originated from animal studies exploring the transjugular route for imaging the biliary tree. The inadvertent portal vein puncture that occurred led Josef Rosch to consider this route as a potential way of decompressing the portal vein. In 1969 he discussed the potential of a radiological portacaval shunt. ${ }^{8} 9$ Early efforts at TIPSS were disappointing with poor primary patency of 2 weeks at most in animal models. ${ }^{10}$ Further developments in the late 1970s with balloon angioplasty improved secondary patency rates. ${ }^{11}$ The first clinical application of TIPSS in humans was in 1982 when Colapinto created a balloon dilated intrahepatic porto-sytemic shunt, ${ }^{11}$ in patients with cirrhosis and variceal bleeding. Clinical efficacy remained poor with high mortality from variceal rebleeding due to poor patency, until the introduction of the expandable $10 \mathrm{~mm}$ Palmaz stents later in the decade which offered much improved long-term patency in animal models. ${ }^{12}$ The first clinical application of TIPSS using expandable metal stents was in 1988 by Martin Rossle and Joerg Richter and colleagues from Freiburg who used Palmaz stents in a $9 \mathrm{~mm}$ channel. ${ }^{13}$ These early procedures lasted on average 8 hours and indeed the Freiberg programme was stopped briefly but recommenced in 1990 when Jean-Marc Perarnau introduced ultrasound guided portal vein puncture, dramatically reducing the procedure time. Seminal papers from the same group and from San Francisco heralded the clinical introduction of TIPSS.
Further clinical indications followed with TIPSS being used for ascites. However, the limitations of bare stents, namely shunt insufficiency became increasingly apparent. The introduction of bespoke PTFE-covered stents which featured a bileresistant coating and covered the entire tract greatly improved shunt patency. ${ }^{14}$ with subsequent reduced need for shunt interventions. The indications for TIPSS thus became broarder with the use of TIPSS in Budd Chiari syndrome. ${ }^{4}$

\section{INDICATIONS FOR TIPSS TIPSS for variceal bleeding}

The place of rescue TIPSS in the management of patients with active variceal bleeding refractory to endoscopic therapy is established despite the lack of RCTs. ${ }^{15-17}$ A recent large observational study of salvage TIPSS showed that pre-TIPSS intensive care unit stay was associated with poor outcomes. ${ }^{18}$ The authors commented on the futility of salvage TIPSS in patients with Child-Pugh score (CPS) $>13$. The role for TIPSS in the secondary prophylaxis of variceal bleeding is more debatable. When comparing bare TIPSS with endoscopic therapy, TIPSS results in reduced rebleeding, but increased hepatic encephalopathy and no difference in survival. ${ }^{19}$ Recent RCTs of TIPSS compared with endoscopic therapy in combination with drug therapy again show that variceal rebleeding is reduced with TIPSS. ${ }^{20-22}$ In a trial of TIPSS vs HVPG response guided drug therapy there was reduced rebleeding with TIPSS but this difference was not so marked in HVPG responders. ${ }^{20}$ This trial also showed that beyond 6 weeks there was no difference in rebleeding or mortality in the two arms. Hepatic encephalopathy was increased in two trials, ${ }^{20} 21$ although in one trial there was no difference in long-term hepatic encephalopathy when TIPSS was compared with VBL and NSBB. ${ }^{21}$ Another trial of TIPSS vs VBL plus NSBB in patients with cirrhotic portal vein thrombosis showed no difference in hepatic encephalopathy. ${ }^{22}$ This trial is notable for a high rate of recanalisation in the TIPSS arm (95\% vs 70\%) despite a significant number of patients having occlusion of the main portal vein and cavernoma. In all these trials there was no difference in survival, which may be related to the minimal impact of variceal rebleeding and TIPSS on survival after the acute bleeding episode, in contrast to early TIPSS as discussed below. ${ }^{20-24}$ TIPSS has been shown to be more effective than tissue adhesives in preventing variceal rebleeding in patients with gastric varices, with no differences in survival or complications in a RCT. ${ }^{25}$ The role of adjunctive variceal embolisation with TIPSS is not clear due to heterogeneity of studies with regards to the use of bare or covered stents and study methodology, and further controlled studies with covered stents are required. $^{26}$

The concept that placement of a TIPSS early after endoscopic control of the index variceal bleed was first published by Monescillo et al using HVPG $>20 \mathrm{mmHg}$ to select patients for early TIPSS within 24 hours of index variceal bleed. The trial demonstrated better outcomes with improved survival in the early TIPSS arm compared with standard of care. ${ }^{27}$ However, only bare stents were used and standard of care did not reflect current practice. This was followed by the trial by Garcia-Pagan et al which reported better 12-month transplant-free survival in the early TIPSS group in Child's C patients or Child's B patients actively bleeding at the time of endoscopy ((86\% vs $61 \%$, $\mathrm{P}=0.001$; ARR, 25\%; 95\% CI, 2 to 48 ; NNT, 4.0 patients; 95\% CI, 2.1 to 50.0$).{ }^{28}$ The definition of 'early' was within 72 hours of endoscopically controlling the bleed. The standard of care was banding in combination with drug therapy. Patients with gastric varices gastro-oesophageal varices (GOV)1 and GOV2 
were included. This was followed by a retrospective post-RCT surveillance study by the same group screening 659 patients of whom 584 were excluded. ${ }^{29}$ Again they found an 86\% 12-month survival but only a trend to improvement in survival compared with endoscopy and drug therapy. ${ }^{29}$ A recent RCT from a single centre in China of early TIPSS $(n=86$, TIPSS within 72 hours of index endoscopy) vs standard of care $(n=46)$ reported better transplant-free survival at 6 weeks and 1 year (HR 0.50, 95\% CI 0.25 to $0.98 ; \mathrm{P}=0.04)$ and improved control of bleeding or rebleeding with early TIPSS (HR 0.26 (95\% CI $0 \cdot 12$ to $0 \cdot 55$; $\mathrm{P}<0 \cdot 0001) .{ }^{30}$ There was no difference in the incidence of hepatic encephalopathy. The benefit was seen in all groups regardless of active bleeding or stage of liver disease. It is important to note that all patients with Child's B and C disease were included irrespective of active bleeding, and that $75 \%$ of patients had chronic hepatitis B (HBV) infection (33\% HBV-DNA negative). Therefore, antiviral therapy could have influenced outcomes in addition to TIPSS, and the difference in predominant aetiology would suggest the results may not be applicable to the developed world. Furthermore, endoscopic sclerotherapy was used in more than $5 \%$ of patients, which is not in keeping with current international guidelines where VBL is recommended. ${ }^{31}{ }^{32}$ A RCT from the UK of early TIPSS in 58 patients with Child-Pugh score $\geq 8$, published in abstract form, showed no difference in survival (HR 1.154 (95\%CI 0.3289 to 3.422 ); P 0.79 ) nor rebleeding regardless of severity of liver disease or active bleeding . ${ }^{33}$ The 1 -year transplant-free survival in the control arm was significantly better than in the 2010 study (76\% vs 61\%), ${ }^{28}$ suggesting improvements in overall care of patients with acute variceal bleeding in the past decade, and extrapolation of results from the 2010 study to the present time needs careful consideration. It is clear from these RCTs that rescue TIPSS, necessary in the 10\%-31\% of the control arm due to refractory rebleeding, was associated with very poor outcomes.

There have been a number of retrospective and prospective audits with variable results. ${ }^{134-37}$ The French study reported better outcomes with early TIPSS but only $6.7 \%$ of those eligible for early TIPSS had this undertaken and this group tended to have less severe liver disease and it was the liver disease severity which correlated with survival rather than early TIPSS. ${ }^{1}$ One of the major challenges with early TIPSS was found to be the logistical issue of arranging a procedure as an 'emergency' in a stable non-bleeding patient, even in centres with keen multidisciplinary teams. The study also showed that some clinicians were not convinced that early TIPSS would be beneficial for their patients. Recent data has led to some debate regarding the inclusion criteria for early TIPSS. ${ }^{136-39}$ While Child's C disease has been shown consistently to correlate with improved survival following early TIPSS, this has not been the case for Child's B patients with active bleeding. ${ }^{136-39}$ A recent large observational study from China showed that patients with Child's B disease only obtain benefit from early TIPSS with regards to 1-year survival if they had active bleeding. However, the findings must be interpreted with caution in light of the intraobserver variability and heterogeneity of reporting active bleeding. ${ }^{39}$ Furthermore, patients with Child's A disease were also included. Thus, the latter criteria is controversial and further controlled studies are necessary to confirm the utility of this criteria in selecting patients for early TIPSS. A recent observational study also showed that patients with a MELD score of $\geq 19$ are likely to benefit from early TIPSS, ${ }^{38}$ a finding confirmed by Lv and colleagues. ${ }^{39}$

A systematic review of two RCTs and two observational studies comparing early TIPSS with standard of care showed reduced mortality with early TIPSS $(\mathrm{OR}=0.38,95 \% \mathrm{CI}=0.17$ to 0.83 , $\mathrm{P}=0.02$ ) with moderate heterogeneity. ${ }^{36}$ There was a significant reduction in rebleeding with early TIPSS and no difference in hepatic encephalopathy. However, the authors concluded that further study was required to identify factors associated with poor prognosis after early TIPSS. Moreover, the recent RCTs by Lv et $\mathrm{al}$ and Dunne et al were not included. ${ }^{30} 33$

It is not clear from these studies if there is a maximal threshold of severity of liver disease beyond which there is no benefit from early TIPSS. In conclusion, the data to support universal adoption of early TIPSS in all high-risk groups currently is inadequate. A multi-centre trial collecting large numbers of patients is a research priority.

Ectopic variceal bleeding can be challenging to manage. The evidence for TIPSS in the management of bleeding ectopic varices is based on case series. ${ }^{40-45}$ Earlier reports showed excellent results for initial haemostasis, although rebleeding occurred in between $18 \%-42 \%$ of patients despite a patent shunt, leading the authors to recommend adjunctive measures such as coil embolisation or thrombin injections. ${ }^{40-44}$ The largest multicentre study of 53 patients found that TIPSS was a good option for those patients with stomal varices in particular. ${ }^{45}$ Covered stents were used in $85 \%$ of patients. Rebleeding occurred in up to $32 \%$ of patients and was related to MELD score, sites other than enterostomy and previous local therapy. Rebleeding was noted to be $50 \%$ in those with bleeding duodenal varices. An interesting observation was that neither post-TIPSS portal pressure gradient (PPG) at a threshold of $12 \mathrm{~mm} \mathrm{Hg}$ nor coil emoblisation influenced rebleeding rates, although the numbers were small.

The evidence for TIPSS in the management of portal hypertensive gastropathy (PHG) is limited to case reports and small case series. ${ }^{46-48}$ The severity of liver disease, the presence of oesophageal varices and endoscopic therapy for oesophageal varices have been reported to influence the incidence of PHG. ${ }^{49}$ TIPSS has been found to be successful in improving the appearances of PHG and reducing transfusion requirements in patients refractory to conservative therapies with NSBB and iron replacement. ${ }^{46-48}$ It is important to differentiate PHG from gastric antral vascular ectasia (GAVE). GAVE has characteristic endoscopic appearances and can co-exist with PHG. ${ }^{50} 51$ The management of clinically significant bleeding from GAVE is challenging and options include medical therapies such as tranexamic acid, and endoscopic therapies such as argon plasma coagulation, band ligation and radiofrequency ablation. ${ }^{51-53}$ In refractory cases, surgical antrectomy can be considered in selected patients. TIPSS does not have a role in the management of bleeding solely from GAVE, although it could be considered where there is co-existing PHG.

Figure 1 is a summary of the recommendations.

\section{Recommendations: TIPSS for variceal bleeding}

- In patients who have gastro-oesophageal variceal bleeding refractory to endoscopic and drug therapy as defined by Baveno 6 critera, ${ }^{32}$ covered TIPSS is recommended (strong recommendation, moderate-quality evidence). Salvage TIPSS is not recommended where the Child-Pugh score is $>13$ (strong recommendation, low quality of evidence).

- In patients who have Child's C disease (C10-13) or MELD $\geq 19$, and bleeding from oesophageal varices or GOV1 and GOV2 gastric varices and are haemodynamically stable, early or pre-emptive TIPSS should be considered within 72 hours of a variceal bleed where local resources allow (weak recommendation, moderate quality of evidence). However, large 


\section{Portal hypertensive bleeding}

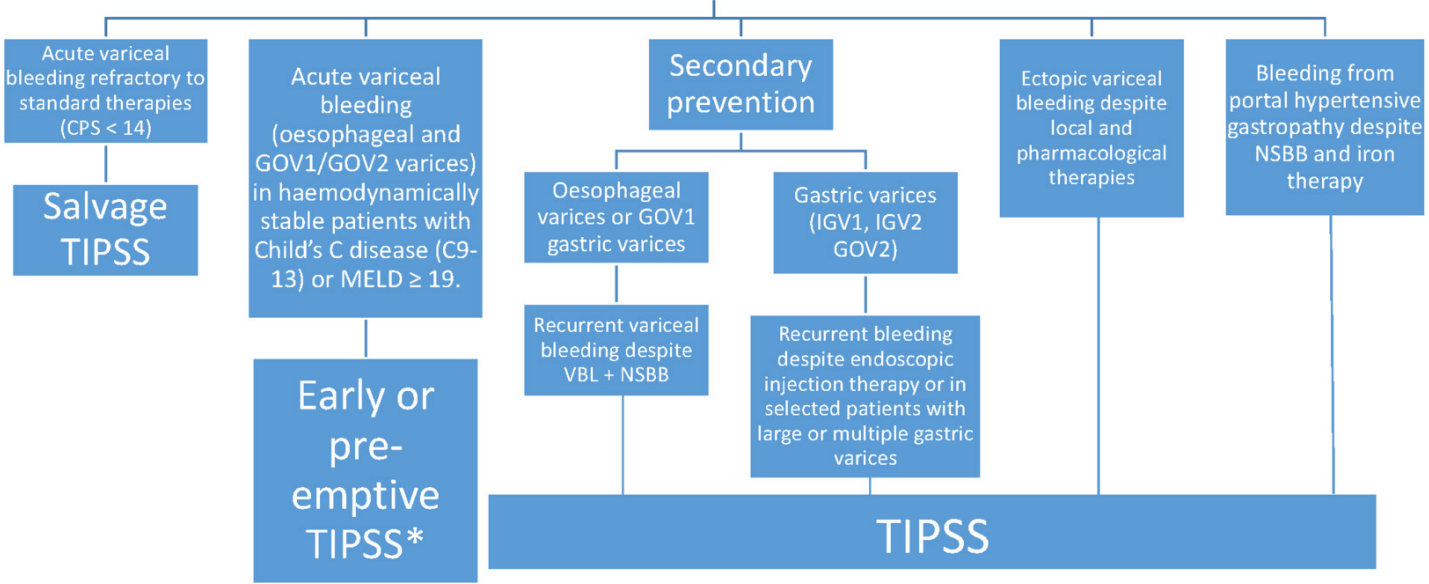

Figure 1 Summary of recommendations for TIPSS in portal hypertensive bleeding. * Further research is required to determine whether patients with Child's B disease and active bleeding or with MELD 12-18 benefit from pre-emptive TIPSS.

multi-centre RCTs are necessary to determine whether patients with Child's B disease and active bleeding or with MELD 12-18 benefit from early pre-emptive TIPSS.

- In secondary prevention of oesophageal variceal bleeding, TIPSS can be considered where patients rebleed despite the combination of VBL +NSBB taking into account the severity of rebleeding and other complications of portal hypertension, with careful patient selection to minimise hepatic encephalopathy (weak recommendation, moderatequality evidence). Further large controlled trials are required to investigate the role of TIPSS as first-line therapy in secondary prevention (strong recommendation, low quality of evidence).

- In secondary prevention of gastric variceal bleeding, TIPSS \pm embolisation is recommended where patients rebleed despite endoscopic injection therapy (strong recommendation, moderate-quality evidence). TIPSS \pm embolisation can also be considered in selected patients with large or multiple gastric varices as first-line therapy in secondary prevention (weak recommendation, moderate-quality evidence).

- In patients with bleeding from ectopic varices refractory to local and pharmacological therapies, TIPSS usually with embolisation is suggested (weak recommendation, lowquality evidence).

- In patients with bleeding from portal hypertensive gastropathy (PHG) refractory to NSBB and iron therapy, TIPSS may be considered (weak recommendation, low-quality evidence).

TIPSS for ascites, hepatic hydrothorax and hepatorenal syndrome TIPSS for ascites

The initial randomised studies of TIPSS vs large-volume paracentesis (LVP) for patients with refractory and/or recurrent ascites published between 1996-2004 came to varying conclusions with regard to survival. ${ }^{54-58}$ However, these studies used relatively outmoded approaches including bare-metal stents and suboptimal approaches to patient selection. These studies generally excluded patients with more severe liver disease such as those with high bilirubin and INR, significant encephalopathy and renal failure. Two more recent randomised studies published in 2011 and 2017 both reported improved survival with TIPSS
.5960 It should be noted that the largest study recruited 109 patients, ${ }^{57}$ with the majority including fewer than 65 patients.

Several meta-analyses concluded that TIPSS led to better ascites control at the cost of increased encephalopathy. ${ }^{61-68}$ Importantly, some reported a higher transplant-free survival with TIPSS.

The most recent meta-analysis was published by the National Institute for Health and Care Excellence (NICE) in 2016 and concluded that TIPSS is better at ascites control and improves transplant-free survival, with less renal failure, but more encephalopathy. ${ }^{68}$ Spontaneous bacterial peritonitis and quality of life were similar. NICE also commented that all these patients should be considered for liver transplantation and noted that there was a wide variation in UK practice. They were concerned that many patients were not being offered TIPSS (see section on TIPSS service).

Covered stents appear to have better outcomes including survival, when used for treating refractory ascites. Two retrospective studies comparing bare vs covered stents reported improved survival $+/$-ascites control with covered stents. ${ }^{69} 70$ A further retrospective case-control study of 150 patients with propensity score analysis reported improved survival with covered TIPSS. ${ }^{71}$

In this context it is interesting that the most recent randomised study from France in 2017 compared TIPSS (using a covered stent) vs LVP in recurrent ascites, and reported improved transplant-free survival and similar encephalopathy with TIPSS. ${ }^{59}$ It should be noted that this study took the four centres 7 years to recruit 62 patients.

In contrast to the situation for variceal bleeding, the optimum target PPG when placing TIPSS for refractory ascites remains unclear. With regard to encephalopathy, the earlier TIPSS studies had described significant encephalopathy with bare-metal stents, however a much lower incidence of encephalopathy with $8 \mathrm{~mm}$ PTFE-covered TIPSS has been reported when used to treat variceal bleeding.$^{20} 72$ Whether this can be extrapolated to the situation when TIPSS is used for refractory ascites is unclear. It should be noted that a randomised study comparing $8 \mathrm{~mm}$ vs $10 \mathrm{~mm}$ covered TIPSS for refractory ascites had to be stopped early after the results in the first 45 patients revealed worse ascites control with $8 \mathrm{~mm}$ stents. ${ }^{73} \mathrm{~A}$ recent retrospective study of 171 consecutive patients having 
$10 \mathrm{~mm}$ - or $8 \mathrm{~mm}$-covered TIPSS for refractory ascites reported higher post-TIPSS PPG and greater need for long-term paracentesis with $8 \mathrm{~mm}$ stents, with similar encephalopathy. ${ }^{74}$ In addition, a recent report from the German TIPSS registry on 185 patients, most of whom had TIPSS for refractory ascites, described prolonged survival with $8 \mathrm{~mm}$ vs $10 \mathrm{~mm}$ stents. ${ }^{75}$ Therefore, the optimal diameter of covered TIPSS stents for this indication remains unclear.

The MELD score was initially developed to predict survival post-TIPSS for variceal rebleeding or refractory ascites, then extended to predict survival in various liver disease patient groups. $^{7677}$ Some studies and authors have suggested TIPSS should not be undertaken based on a high (eg $\geq 18$ ) MELD score, however the role of MELD in patient selection remains unclear. ${ }^{78}$ Gaba et al compared various scores including MELD and CPS in the prediction of outcome after TIPSS and found that CPS had the best overall capability at predicting mortality when TIPSS is used for ascites. ${ }^{79}$ In addition, Bureau et al have proposed the use of simple laboratory parameters (bilirubin $<50 \mathrm{umol} / \mathrm{L}$ and platelets $>75 \times 10^{9}$ ) to predict 1 -year survival following TIPSS for refractory ascites. ${ }^{80}$ Further studies on the use of these criteria are required.

Three recent guidelines recommend TIPSS in the management of refractory or recurrent ascites. ${ }^{64968}$ The EASL guidelines also suggested useful parameters to identify higher-risk patients with more advanced liver disease who would not benefit from TIPSS. ${ }^{49}$ These include bilirubin $>50 \mu \mathrm{mol}$ and platelets $<75 \times 10^{9}$, current encephalopathy, active infection, progressive renal failure, severe systolic or diastolic dysfunction, or pulmonary hypertension. Many guidelines and studies have recommended that once a patient is being considered for TIPSS in the context of ascites, liver transplantation should also be considered at that stage for appropriate patients.

Figure 2 is a summary of the recommendations.

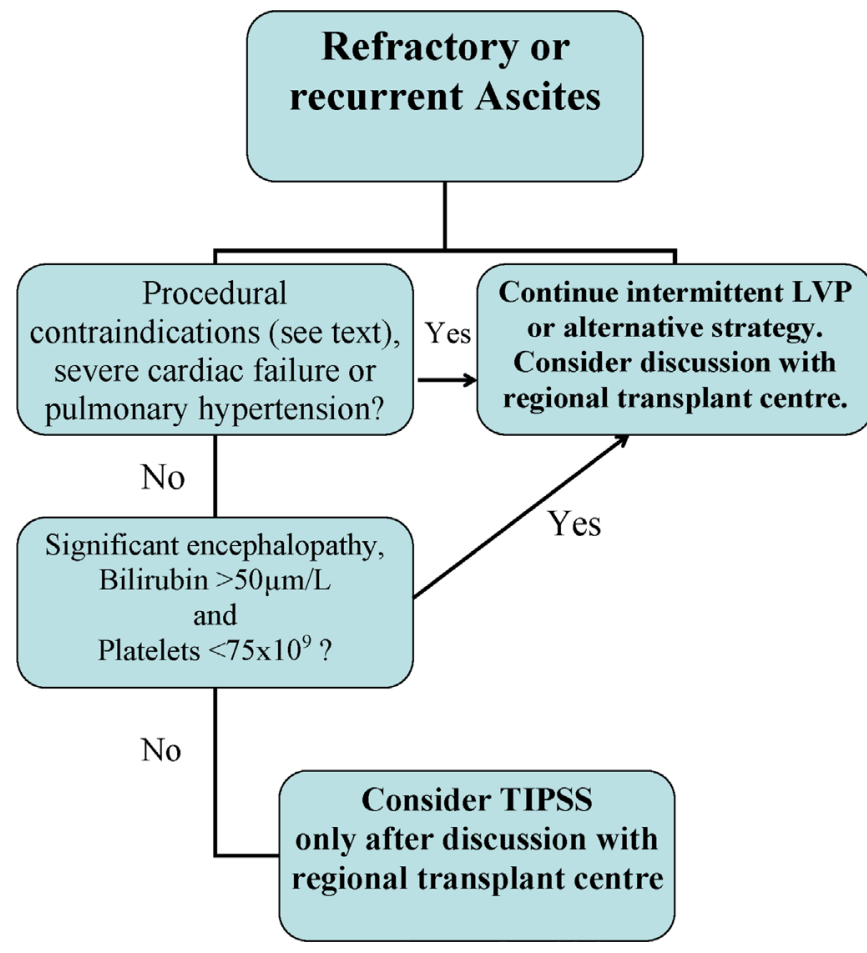

Figure 2 Summary of recommendations for TIPSS in recurrent or refractory ascites.
Recommendations: TIPSS for ascites

- In patients who are eligible for liver transplantation, TIPSS for ascites should only be undertaken after discussion with the regional transplant centre (strong recommendation, very low-quality evidence).

- In selected patients with refractory or recurrent ascites, we recommend insertion of TIPSS provided there are no contraindications to the procedure (strong recommendation, high-quality evidence).

- In addition to the standard TIPSS contraindications, patients who may not benefit from TIPSS for ascites include those with bilirubin $>50 \mu \mathrm{m} / \mathrm{L}$ and platelets $<75 \times 10^{9}$, pre-existing encephalopathy, active infection, severe cardiac failure or severe pulmonary hypertension (strong recommendation, moderate- quality evidence).

\section{TIPSS for hepatic hydrothorax}

Hepatic hydrothorax is an uncommon complication of endstage liver disease, affecting approximately $10 \%$ of individuals. ${ }^{81}$ Refractory hepatic hydrothorax is defined by a failure to control symptomatic fluid accumulation through optimisation of sodium intake and diuretic treatment. Management is challenging: thoracocentesis is recommended where there is respiratory compromise but where repeated intervention is required, TIPSS has been suggested. The published evidence supporting this approach is comprised of a number of case reports and six case series including 208 participants. ${ }^{82-87}$ These studies have been pooled in a meta-analysis. ${ }^{88}$ It is worth noting that the mortality estimates are different from those of the individual studies, and interpretation of the pooled estimates must take this into account. Good clinical responses are observed in a substantial proportion of patients treated with TIPSS and patient selection is critical to that. These studies indicate a probability of complete response of the hydrothorax of between $42 \%$ and $79 \% .{ }^{82-87}$ However, there was appreciable early mortality reported in all but one of these series. ${ }^{85}$ There is clearly a risk of early mortality related to TIPSS for hepatic hydrothorax that appears related to progressive liver disease. The studies reported were done more than a decade ago and only one includes patients treated with PTFE covered TIPSS. ${ }^{82}$ Furthermore, since there are no studies comparing TIPSS with standard treatment, consequently, there is no available information on the impact of TIPSS on comparative survival in this population. Improvements in patient selection for TIPSS in general are likely to have reduced the reported early post-TIPSS mortality in patients with hydrothorax but there are no published data to support this.

\section{Recommendation: TIPSS for hydrothorax}

- Selected patients with refractory hepatic hydrothorax may be considered for TIPSS insertion. (strong recommendation, moderate-quality evidence).

\section{TIPSS for hepatorenal syndrome}

The severity of liver disease usually precludes TIPSS in patients with severe portal hypertension-related renal dysfunction (type 1 and type 2 HRS). The poor residual liver function does not cope with the reduced portal inflow, with an increased risk of hepatic encephalopathy, and a potential unmasking of cirrhotic cardiomyopathy. Although, renal function has been observed to improve following TIPSS, TIPSS for HRS remains experimental. $^{568990}$ A recent systematic review demonstrates the paucity of good-quality data, and heterogeneity with regards to patient selection and outcomes. ${ }^{91}$ Furthermore, in type 2 HRS 
patients with more severe renal dysfunction were excluded. The rate of hepatic encephalopathy approached 50\% which is significantly higher than for other indications. Finally, most studies used bare stents. Liver transplantation should be considered.

\section{Recommendation: TIPSS for hepatorenal syndrome}

- Although, renal function has been observed to improve following TIPSS, TIPSS for HRS (type 1 and type 2) remains experimental (weak recommendation, very low level of evidence).

\section{TIPSS and Budd-Chiari syndrome}

BCS is defined as obstruction of the hepatic venous outflow from the level of the sinusoids to the inferior vena cava. In most cases, BCS is primary, but secondary causes include tumour invasion or large hepatic cysts. ${ }^{92}$ In primary BCS, a procoagulant condition such as JAK2 positive myeloproliferative neoplasm is present in nearly $50 \%$ of patients. ${ }^{93}$ The stepwise management includes anticoagulation in all patients, and hepatic vein interventions in symptomatic BCS. ${ }^{92}$ The timing of TIPSS has been debated, but in the authors' opinion it is indicated when hepatic vein interventions is unsuccessful or not possible. TIPSS may also be considered where there is an acute presentation and in smallvessel BCS. Where there is acute liver failure, patients may be eligible for super urgent liver transplantation. Due to the rarity of BCS no RCTs exist of TIPSS for BCS. It is important to note that BCS can present in a different way with more involvement of IVC in countries such as India and China. ${ }^{95,96}$ Furthermore, the management strategies are more heterogeneous with regards to anticoagulation.

Numerous observational studies demonstrate very good long-term outcomes despite TIPSS being technically more challenging. ${ }^{43-104}$ The largest series demonstrate very good symptom resolution exceeding 70\%, and excellent long-term outcomes with 5-year survival rates exceeding 70\%. Primary patency rates are improved with the use of PTFE-covered stents. A direct intrahepatic porto-caval shunts (DIPS) procedure is also an alternative to the classic TIPSS where all hepatic veins are occluded. A tract is created by direct puncture from the IVC through the liver to the portal vein. ${ }^{105}$ The clinical outcomes following DIPS are similar to classical TIPSS. ${ }^{105}$ TIPSS is associated with the risk of hepatic encephalopathy which had been reported in up to $15 \%$ of patients. ${ }^{93}$ The risk of hepatic encephalopathy is considerably less with HV interventions which is more physiological. Recent data from a multicentre EU study ${ }^{102}$ suggests that Rotterdam Class III patients should also be considered for a TIPSS at an early stage, confirming previous data. ${ }^{106}$ This requires further validation. The BCS-TIPS score $>7$ has been consistently shown to predict poor outcomes in several studies, and such patients should be considered for liver transplantation. ${ }^{29} 93102$ It is essential all patients with BCS are managed in specialised centres with an experienced multidisciplinary team comprising hepatology, interventional radiology and haematology, with access to liver transplantation which has a good outcome in selected cases. ${ }^{107} 108$

\section{Recommendations: TIPSS for Budd-Chiari syndrome}

- It is recommended that all patients with BCS are managed in centres of high expertise which are either transplant centres or have formal links with a liver transplant centre (strong recommendation, very low-quality evidence).

- TIPSS is recommended where patients fail to respond to medical therapy with anticoagulation or hepatic vein interventions (strong recommendation, moderate-quality evidence). TIPSS can be considered where hepatic vein interventions is not technically feasible (weak recommendation, low-quality evidence).

- Patients with poor prognostic scores (see text), or those who do not respond to anticoagulation and radiological therapies, have a poor prognosis and should be considered for liver transplant assessment (strong recommendation, moderate-quality evidence).

\section{TIPSS prior to non-hepatic surgery in patients with portal hypertension (prophylactic TIPSS)}

A rare indication for TIPSS is prior to elective non-hepatic surgery in patients with portal hypertension. This can reduce the potential deleterious effects of portal hypertension such as abdominal varices which can increase the risk of bleeding. There is a marked paucity of data. A recent systematic review studied all fully published studies. ${ }^{3}$ All publications are retrospective in nature. The largest series was with 18 patients with many case reports with just one patient. There is also a marked heterogeneity with regards to patient selection based on the severity of liver disease and criteria for successful TIPSS prior to surgery. However, in almost all cases, curative surgery was performed and there did not appear to be increased mortality above what would be expected. Possibly mortality was lower than in those patients with cirrhosis and portal hypertension without a TIPSS. However, there is a real risk of publication bias, and all data must be interpreted cautiously. Furthermore, a recent retrospective study comparing 66 patient with TIPSS prior to abdominal surgery (predominantly colorectal surgery) to 68 patients without a TIPSS pre-surgery showed no differences in post-operative complications and mortality. ${ }^{109}$ A retrospective study of patients with idiopathic non-cirrhotic portal hypertension (INCPH) undergoing non-hepatic surgery did not find that portal decompressive procedures prior to surgery affected outcomes, although the sample size was small. ${ }^{110} \mathrm{~A}$ prospective study showed the value of HVPG in predicting outcomes in cirrhotic patients undergoing non-hepatic surgery, with no patient having HVPG $<10 \mathrm{mmHg}$ developing decompensation. ${ }^{111}$ The American Gastroenterology Association does not recommend routine TIPSS prior to surgical procedures in patients with cirrhosis and portal hypertension. ${ }^{112}$ Therefore, in view of the lack of evidence, this indication for TIPSS has to be carefully balanced against that of the risk of TIPSS itself.

\section{Recommendation: prophylactic TIPSS}

- There is insufficient data to recommend TIPSS prior to nonhepatic surgery, although in compensated cirrhotic patients undergoing curative surgery for cancer there may be a role (weak recommendation, low-quality evidence). Further research is recommended, with the focus on careful patient selection.

\section{TIPSS and idiopathic non-cirrhotic portal hypertension}

INCPH or porto-sinusoidal vascular liver disease ${ }^{113}$ is a rare cause of intrahepatic portal hypertension. Its diagnostic criteria have been described previously, and rests on liver histology which shows an absence of cirrhosis and the presence of subtle lesions such as hepatoportal sclerosis or nodular regenerative hyperplasia. ${ }^{114}$ There are only six published observational studies on the utility of TIPSS in INCPH. ${ }^{215-119}$ The largest of these from China compared patients with INCPH $(n=76)$ with a matched control group of cirrhotic patients $(n=76)$ over a median follow-up of 34 months. The indication for TIPSS was 
variceal bleeding in all cases. Another study included a cohort of 41 patients from seven EU centres followed up over a mean of 27 months. In this study $80 \%$ of patients had a covered stent. The third study of 25 patients from a single centre in France extended over a mean follow-up of 39 months. ${ }^{118}$ The fourth study included 11 patients from two EU centres over a mean follow-up of 112 months. ${ }^{116}$ Two other studies have fewer than 10 patients. ${ }^{115} 117$

The main observations are of overall good clinical outcomes with good control of ascites and 5-year survival of 60\%-89\%. The rate of hepatic encephalopathy was high in most of these studies at more than $35 \% .^{2} 114116-118$ The study by Lv et al showed lower mortality (12\% vs 26\%) and hepatic encephalopathy (32\% vs 14\%) in the INCPH group compared with cirrhotic patients. ${ }^{119}$ Ascites, malignancy, immunological disorders and female sex were associated with mortality. Bare stents had higher bleeding and shunt dysfunction. It should be noted that portal vein thrombosis was higher in the cirrhotic group, and $8 \mathrm{~mm}$ stents were used which could explain the low rates of encephalopathy. Having extra-hepatic co-morbidities, ascites as an indication and creatinine predicted worse survival, but no risk factor was identified after multivariate analysis in one of the largest of these studies. ${ }^{2}$ The risk of procedural bleeding seemed rather high in the study by Bissonnette et al, and authors suggested this may be due to increased arterialisation of the liver. ${ }^{2}$ The risk of associated splanchnic vein thrombosis was 39\%, although this was not associated with mortality or rebleeding. Conversely, the presence of portal vein cavernoma led to increased morbidity in the study by Regnault et al. ${ }^{118}$

\section{Recommendation: TIPSS for idiopathic non-cirrhotic portal hypertension}

- The indications for TIPSS in INCPH should be similar to cirrhosis, and covered stents are preferred. The selection criteria should also be similar to cirrhosis with particular attention to risk factors for hepatic encephalopathy (weak recommendation, low-quality evidence).

\section{TIPSS in portal vein thrombosis}

Portal vein thrombosis (PVT) has traditionally been seen as a contraindication to TIPSS placement. However, there have been a number of reports and small series where transjugular shunts have been successfully placed, from 1993 onwards. ${ }^{120}$ Indications have included patients with acute portal vein thrombosis and ischaemic bowel, ${ }^{121}$ cirrhotic patients with PVT and variceal bleeding, ${ }^{122}$ and patients with PVT where the degree of thrombosis is felt to compromise liver transplantation. ${ }^{123}$ These studies have been heterogeneous, including cirrhotic patients, patients with acute and chronic portal vein thrombosis, ${ }^{124}$ those with partial or complete thrombosis, and the presence or absence of cavernous transformation. Scoring systems that provide some objective analysis of the burden of thrombosis exist, but are not routinely used, further compounding the difficulty in assessing the role of TIPSS in portal vein thrombosis. ${ }^{125} 126$

A meta-analysis identified a 60\%-99\% technical success rate (pooled 86\%), and likely reflects a significant reporting bias, with a $25 \%$ incidence of hepatic encephalopathy. ${ }^{127}$ Another systematic review reported similar findings, although heterogeneity was noted due to cavernous transformation. ${ }^{128}$ Thrombolysis was associated with more complications,

As mentioned earlier, there has been a single clinical randomised trial ${ }^{22}$ in a population of cirrhotic patients that had previous bleeding, that identified a lower re-bleeding rate in the
TIPSS group compared with the group that received banding ligation plus propranolol ((15\%vs $45 \%$ at 1 year, $25 \%$ vs $50 \%$ at 2 years). There was no significant difference in survival or encephalopathy. No published image scoring system was used.

Technical aspects which may facilitate success are reported and include: visibility of intra-hepatic PVT branches on US ${ }^{124}$ transplenic/transhepatic "rendezvous" technique; ${ }^{129}$ local thrombolysis; ${ }^{130}$ and transjugular local thrombolysis and portal pressure guided stent placement. ${ }^{121}$

The publication bias skews the ability to make firm recommendation. Clearly at the advanced end of the technical spectrum of TIPSS placement, the absence of clear factors predicting success (apart from the visibility of intrahepatic portal vein radicles) limits referral criteria. At the same time, the therapeutic void between anticoagulation and major gut resection in patients with acute splanchnic vein thrombosis, and the ability to successfully convert patients into transplant candidates, means that units prepared to attempt these procedures should not be discouraged. Furthermore, the advance of digital image transfer platforms means that patients with PVT can be discussed with these centres without the patient automatically needing transfer.

\section{Recommendations: TIPSS in portal vein thrombosis}

- PVT should not be considered an absolute contraindication to TIPSS placement, although the presence of cavernoma is associated with a significantly high failure rate (strong recommendation, high-quality evidence).

- Patients with acute PVT should be discussed with experienced units (weak recommendation, very low-quality evidence).

- Cirrhotic patients with PVT and variceal bleeding should be discussed with experienced units (weak recommendation, low-quality evidence).

\section{PATIENT SELECTION}

Figure 3 is a summary of the key aspects of patient selection.

\section{Hepatic encephalopathy}

\section{Pre-TIPSS assessment of encephalopathy}

As with all portosystemic shunts, the major complication postTIPSS is HE. This is particularly heartbreaking for the relatives/ carers, who will be the first to notice changes in cognition. Phrases such as "I no longer recognise my husband/wife" reflect a poor outcome, especially when the TIPSS has been a palliative procedure in someone with recurrent ascites. The incidence of encephalopathy has been quoted as high as $55 \%$ and is dependent on patient and attainment factors: assiduous searching for encephalopathy will identify a higher incidence.

Every effort needs to be made to identify those at risk of postTIPSS HE, especially in the elective setting. This is harder to do when the TIPSS is being considered in an emergency, and under these circumstances, a history may be all that is available, for example, a history of debilitating encephalopathy in someone with an acute variceal bleed is a contraindication to a TIPSS unless there is a major competing portosystemic shunt that can be embolised.

Patient-related factors perhaps predictably include: age, severity of liver disease, history of preceding encephalopathy ${ }^{131}$ and size of shunt. A Child-Pugh score equal or greater than 10 was a proposed cut-off point. The recently recognised additional risk factor of diabetes may well reflect altered renal handling of ammonia. ${ }^{132}$ This latter consideration is increasingly important, as many of the referrals for TIPSS for diuretic resistant ascites 


\section{TIPSS}

Patient Selection

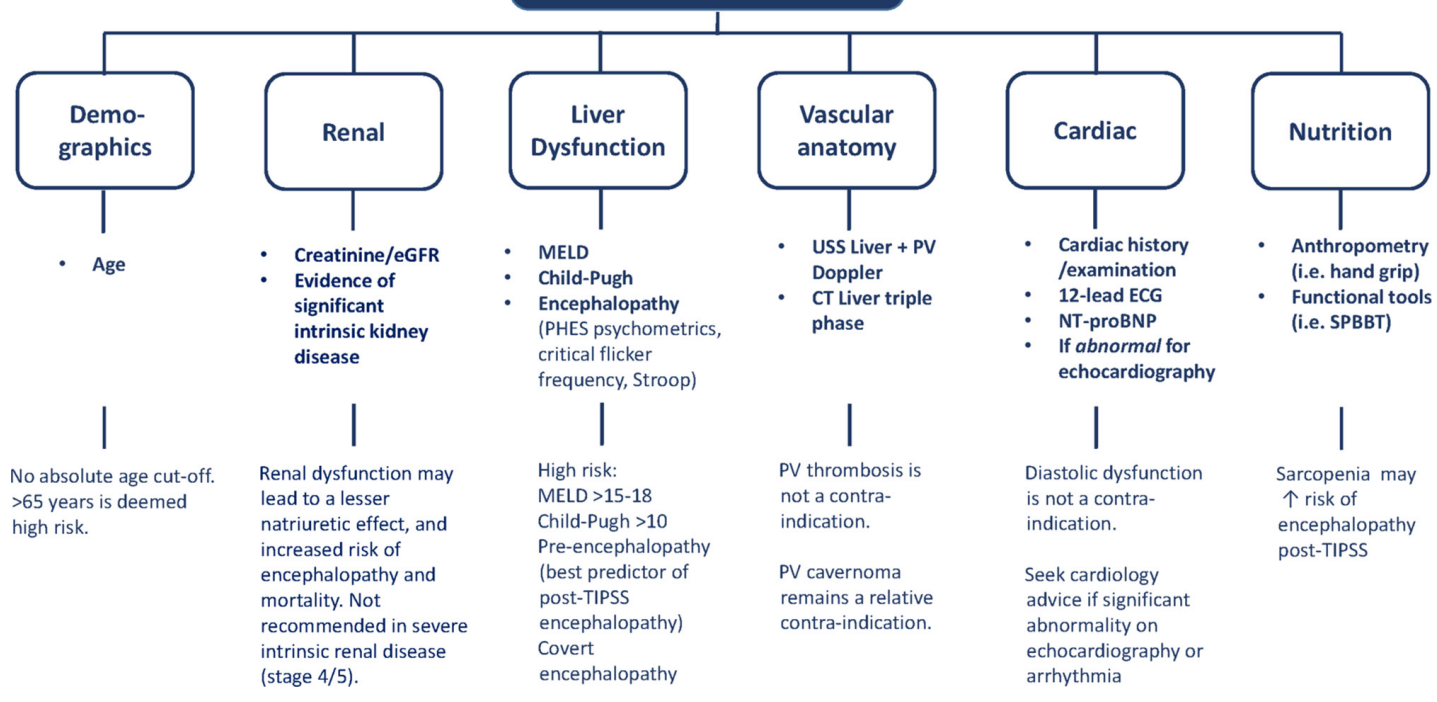

Figure 3 Summary of recommendations for patient selection prior to TIPSS.

are in patients who have non-alcoholic steatohepatitis (NASH) and who are diabetic.

While these simple clinical markers are easy to obtain, most elective patients will have well-preserved liver function. The major advance has been the recognition of the clinical disorder "covert" or subclinical encephalopathy. This is a disorder in which patients with chronic liver disease exhibit specific, reversible, quantifiable, neuropsychological or electroencephalographic abnormalities in the absence of clinically obvious mental or neurologic defects. ${ }^{133}$ The critical next step is the identification that covert hepatic encephalopathy predicts the development of overt hepatic encephalopathty. ${ }^{134}$ This has driven the search for accurate techniques that identify covert encephalopathy, and parameters which predict the development of overt encephalopathy post-TIPSS.

EEG has been one of the most utilised investigations prior to patients undergoing TIPSS procedure but it has limitations. Visual EEG alone will underevaluate the risk of encephalopathy ${ }^{135}$ and the use of spectral analysis using the P3-4 lead has been shown to be superior to visual assessment alone. ${ }^{136}$ A value of less than $8 \mathrm{hz}$ is abnormal.

The Stroop test is a downloadable application that has shown sensitivity in diagnosis covert encephalopathy. ${ }^{137}$ It is cheap and easily reproducible. It is underused in clinical practice.

Critical flicker frequency (CFF) involves the patient observing a flickering image. The frequency at which the image "fuses" from flickering to a constant is defined as the CFF, and patients with encephalopathy will have a lower value compared with a normal individual. The absence of a pre-TIPSS history of overt hepatic encephalopathy and a CCF value of $>39 \mathrm{~Hz}$ had a $100 \%$ negative predictive value for post-TIPSS overt encephalopathy. ${ }^{138}$

Psychometric hepatic encephalopathy score (PHES) psychometric testing is a well validated tool for establishing the presence of encephalopathy, both covert and overt. ${ }^{139}$ This technique has been studied prospectively, is readily available and utility confirmed. ${ }^{140}$ A patient with refractory ascites with a normal PHES score has a 90\% probability of remaining free of $\mathrm{HE}$ post-procedure. ${ }^{138}$

Diagnostic guidelines have recommended that a diagnosis of covert encephalopathy requires at least two abnormal psychometric tests or an abnormal PHES, and, wherever possible a quantitative EEG. ${ }^{141}$ Patients who have evidence of covert encephalopathy should not undergo a TIPSS unless additional techniques are employed.

\section{Post-TIPSS encephalopathy management}

Despite attempts to carefully select patients for TIPSS, HE remains the most common complication following TIPSS, affecting almost one-third of patients. The management of postTIPSS HE is challenging and is medical or radiological or a combination of both.

Basic encephalopathy management should be followed. Biochemical abnormalities should be corrected, night sedation ceased and lactulose prescribed in order to achieve two bowel movements per day. Proton-pump inhibitors should be stopped. If $\mathrm{HE}$ continues, rifaxamin should be started. If $\mathrm{HE}$ continues then options in escalating order are competing shunt embolisation, TIPSS stent reduction and TIPSS occlusion. The latter is necessary in approximately $5 \%$ of patients with post-TIPSS HE. ${ }^{142}$

\section{Recommendations: TIPSS and hepatic encephalopathy}

- TIPSS may worsen or precipitate encephalopathy. Patients undergoing elective TIPSS should be screened for covert and overt encephalopathy (strong recommendation, high-quality evidence).

- Screening should ideally be at least two of the following: PHES testing, Stroop testing, CFF and Spectral Enhanced or quantative EEG (strong recommendation, moderate-quality evidence).

- The presence of covert hepatic encephalopathy is a relative contraindication to elective TIPSS (weak recommendation, low-quality evidence).

- Although age >65 is not an absolute contraindication, it might increase the risk of encephalopathy and should be taken into account when deciding the eligibility for elective TIPSS (weak recommendation, low-quality evidence).

- Patients who develop encephalopathy following a TIPSS should be managed according to standard guidelines, but 
if encephalopathy continues, consideration should be given to shunt reduction, embolisation or occlusion (weak recommendation, low level of evidence).

\section{Cardiac assessment}

There is a growing awareness that the presence of cirrhosis is associated with significant cardiovascular abnormalities. ${ }^{143}$ This is commonly termed cirrhotic cardiomyopathy and comprises a constellation of cardiac abnormalities, which include myocardial hypertrophy, electrophysiological abnormalities (ie, prolonged QT), decreased ventricular compliance and normal systolic function at rest, but incompetence when under physical or pharmacological stress. ${ }^{144} 145$ The assessment of cardiovascular risk pre-TIPSS is therefore important, as shunting a significant volume of the portal to the central circulation, the cardiac output and right atrial pressures increase by $50 \%$ and $100 \%$, respectively. Despite these physiological changes, the clinical importance of underlying cardiac cardiomyopathy in patients undergoing TIPSS remains a subject of considerable debate. While some argue that cardiac (in particular diastolic) dysfunction predicts worse outcomes after TIPSS, ${ }^{146-149}$ others are more sceptical, as overt cardiac failure is very rarely reported. ${ }^{150-153}$

Of particular interest in the field is diastolic dysfunction, as the incidence approaches $40 \%$ in patients awaiting a TIPSS. ${ }^{146} 154$ Three prospective studies $(n=33-101)$ reported that diastolic dysfunction is related to post-TIPSS mortality within 1 year. ${ }^{146-148}$ It must be noted that these studies solely utilised E/A (early maximal ventricular filling velocity/atrial maximal ventricular filling velocity) ratio $<1.0$ to define diastolic dysfunction (limited by its dependence on cardiac loading conditions and age), lacked an independent echocardiographer and also that only $3 / 144$ reported deaths were attributed to cardiac failure. In contrast, despite pre-TIPSS rates of diastolic dysfunction ranging from 30\%-45\%, five more recent studies (two retrospective studies, $n=27-117$; three prospective studies, $n=15-883$ ) found no relationship between diastolic dysfunction and post-TIPSS survival or cardiac failure. ${ }^{150-153155}$ Although retrospective in design, Modha et al reported that post-TIPSS symptomatic heart disease is rare $(8 / 883 ; 0.9 \%)$ and even when present there was no difference in mortality compared with controls (6.3 vs $12.0 \%$ at 30 days, respectively). ${ }^{153}$ In contrast, a recent prospective French study of 100 patients undergoing TIPSS and a detailed cardiac assessment, highlighted that $20 \%$ were diagnosed with cardiac failure (requiring hospitalisation) within 1 year of TIPSS of who $5 / 20$ died. $^{149}$ It is noteworthy that $55 \%$ had a preceding established diagnosis of heart disease (including moderate-severe aortic stenosis). ${ }^{149}$ There is a large degree of heterogeneity in these studies, and with the exception of the recent French study, ${ }^{149}$ the majority excluded patients with a history of IHD and CVS risk factors, thereby limiting the applicability to the findings to higher-risk individuals.

Serum N-Terminal pro-B-type natriuretic peptide (NT-proBNP) has been shown to predict heart failure in patients with cirrhosis ${ }^{156} 157$ and peri-operative cardiac events in noncardiac surgery. ${ }^{158}$ NT-proBNP has also been shown to correlate with severity of liver disease and QTc interval in cirrhosis. ${ }^{159} 160$ However, there is conflicting data in the setting of TIPSS of whether NT-proBNP is predictive of cardiac events following TIPSS. ${ }^{149} 152$ In the largest afore-mentioned prospective study of 100 patients, NT-proBNP was found to be predictive of cardiac decompensation after TIPSS, but not mortality. ${ }^{149}$ The authors recommended that a NT-proBNP level of less than $125 \mathrm{pg} / \mathrm{mL}$ enabled identification pre-TIPSS of those patients not at risk of cardiac decompensation. ${ }^{149}$

The decision to perform a TIPSS in a high-risk patient, should be reached by a team of a gastroenterologist/hepatologist, interventional radiologist, anaesthetists/intensivists and where appropriate a transplant physician. However, there remains limited data to support the utility of echocardiogram in the absence of a positive cardiac history, examination or ECG (prolonged QT interval) and NT-proBNP) prior to TIPSS. The utility of alternative echocardiographic methods of assessing cardiac function such as left ventricular global longitudinal strain remains a research area. ${ }^{161}$

\section{Recommendations: cardiac assessments}

- A cardiac history, examination, 12-lead ECG and N-Terminal pro-B-type natriuretic peptide (NT-proBNP) should be undertaken in all patients undergoing elective TIPSS insertion (strong recommendation, moderate-quality evidence). Further cardiac evaluation (echocardiogram +/-cardiology consultation) should be undertaken before elective TIPSS if any of these are abnormal (strong recommendation, moderate-quality evidence).

- Elective TIPSS is not recommended in patients with severe left ventricular dysfunction or severe pulmonary hypertension (strong recommendation, moderate- quality evidence).

- Echocardiogram in acute variceal haemorrhage may be inaccurate and should not delay an emergency, potential lifesaving TIPSS insertion (strong recommendation, low-quality evidence).

\section{Nutritional assessment}

Over the past 5 years, our understanding of the impact of sarcopenia and malnutrition on survival in patients with cirrhosis has exponentially grown. As many as $20 \%$ and $50 \%$ of patients with compensated or decompensated cirrhosis, respectively, have sarcopenia. This, in turn, accelerates progression to liver failure and increases the rates of infections, ascites and encephalopathy. Recent international guidelines recommend that all patients with cirrhosis should undergo a rapid nutritional screen and in those deemed at risk of malnutrition, a more detailed expert dietetic assessment (ie, anthropometry, sarcopenia measures) should be undertaken. ${ }^{162}$ However, very few studies have focused on the impact of sarcopenia and malnutrition on the clinical outcomes of TIPSS. To date, a prospective study of 46 patients with cirrhosis from Italy has shown that sarcopenia (on CT) is independently associated with the development of hepatic encephalopathy post-TIPSS. ${ }^{163}$ The authors hypothesised that this maybe be attributed to reduced processing of ammonia. ${ }^{163}$ In addition, a European study of 116 patients with radiological measures of sarcopenia pre and post-TIPSS, highlighted that persistence of sarcopenia post-TIPSS was associated with reduced effectiveness of TIPSS (especially with ascites) and a higher risk of liver failure and mortality. ${ }^{163}$ However, the study included patients where the indication for TIPSS was both variceal bleeding and ascites. Another study published in abstract form of patients undergoing TIPSS for ascites reported that the presence of sarcopenia preTIPSS did not impact on outcomes post-TIPSS. ${ }^{164}$ Even though very few studies exist, these data suggest the need for prospective studies on the role of nutritional assessment both pre- and post-TIPSS. 


\section{Recommendation: nutritional assessment}

- Patients referred for elective TIPSS insertion should undergo a detailed nutritional and functional assessment (weak recommendation, low-level evidence).

\section{Renal function}

Differentiating portal hypertension-related renal dysfunction from intrinsic kidney disease, and acute kidney injury from stable chronic renal disease, is probably important. However, there is limited supporting evidence at present: the RCTs of TIPSS largely excluded patients with intrinsic kidney disease or significant renal dysfunction, with a mean baseline creatinine of

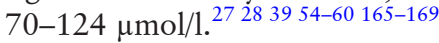

In portal hypertension-related renal dysfunction, reflecting more advanced disease, a higher serum creatinine is predictive of post-TIPSS mortality. ${ }^{77}{ }^{170}$ In portal hypertension-related renal dysfunction and intrinsic kidney disease, a higher baseline serum creatinine may be associated with a lesser natriuretic effect of TIPSS $^{171} 172$ and an increased frequency of the development of hepatic encephalopathy. ${ }^{173}$ The presence of severe intrinsic kidney disease (stage 4/5) may lead to an unacceptably high rate of severe encephalopathy. ${ }^{174}$

The indication for TIPSS may also be relevant. In rescue TIPSS, renal dysfunction is often acute and the key determinant of the risk benefit ratio is multiorgan dysfunction. However, in elective TIPSS for refractory ascites, suitability for a life-prolonging liver transplant and quality of life should be the focus.

\section{Recommendations: renal function}

- In patients with significant intrinsic renal disease (stage 4/5), elective TIPSS is not recommended (strong recommendation, low-quality evidence).

- TIPSS can be considered in patients presenting acutely with variceal bleeding and renal dysfunction (weak recommendation, very low-level evidence).

\section{PROCEDURAL DETAILS}

The indications and pre-implantation work-up of a patient prior to TIPSS is discussed elsewhere. Elective patients should be discussed in a multidisciplinary forum. Implantation of a TIPSS is one of the most technically challenging interventional radiological procedures, and early dialogue with an interventional radiologist is essential. The interventional radiologist should ideally review elective patients in a clinical setting and be intimately involved with the decisions relating to suitability of a TIPSS. Emergency TIPSS (eg, uncontrolled variceal bleeding) will still naturally involve a discussion, which may also include issues of futility. TIPSS in patients with advanced liver disease, encephalopathy and multi-organ failure (especially aspiration) does not usually alter patient outcomes. All risk should be measured against clinical need and anticipated survival benefit.

Accepted contraindications to TIPS ${ }^{175}$

Significant pulmonary hypertension

Heart failure or severe cardiac valvular insufficiency

Rapidly progressive liver failure

Severe or uncontrolled hepatic encephalopathy

Uncontrolled systemic infection or sepsis

Unrelieved biliary obstruction

Polycystic liver disease (though successful cases reports exist)

Extensive primary or metastatic hepatic malignancy

\section{Preparation for TIPSS}

Imaging

Contrast-enhanced CT of liver (portal venous phase) or contrastenhanced MRI of liver is recommended for assessing suitability and planning the TIPSS procedure. In certain circumstances such as significant renal impairment, ultrasound can be used for this purpose, particularly if performed by the TIPSS operator. In the emergency situation, if the patient is well enough to be transferred to the interventional radiology suite, then they are well enough to undergo CT.

\section{Consent}

Consent should follow established principles and local procedures observed to ensure the WHO checklist completed. The PARQ mnemonic (Procedure, Alternatives, Risks, Questions) provides a useful framework. The procedure itself is quoted as having a $5 \%$ major complication rate including a $2 \%$ incidence of procedure-related death, although these figures included data from early series and reflected the emergency situation in which TIPSS was first deployed. Patients should be informed explicitly of the risk of encephalopathy, and intra-abdominal bleeding related to capsular puncture. The American Society of Interventional Radiology Standards of Practice Committee provides an evidence base for these discussions. ${ }^{175}$ Consent should also be obtained if paracentesis or transjugular biopsy is also planned during the same procedure.

\section{Sedation}

It is the authors' opinion that the TIPSS procedure should be performed either under general anaesthetic or with propofolbased deep sedation. The procedure itself may be painful, particularly during the time of intrahepatic balloon dilatation. General anaesthetic, allows controlled breath holds which facilitate portal vein cannulation, and in the emergency situation the airway is protected should variceal bleeding occur. While some high-volume units have successfully used conscious sedation for many years, there was general agreement that this was not an ideal environment to be performing this procedure

Therefore, all patients should be prepared for general anaesthetic as per local policy. All patients should have up-to-date biochemistry (renal and liver function), haematology (full blood count and INR) and an ECG. Patients should be hydrated to facilitate central venous puncture, and to minimise the risk of contrast nephropathy. There is no role for pre-procedure $\mathrm{N}$-acetyl cysteine or bicarbonate. ${ }^{176}$

In patients with tense ascites, large-volume paracentesis should be considered either pre- or peri-procedure in order to facilitate extubation.

\section{Antibiotics}

Routine prophylactic antibiotics are not recommended. If a long/complex procedure is anticipated (when inadvertent biliary puncture may occur) or previous biliary surgery, then prophylactic antibiotics can be given according to local antibiotic policy to cover gram negative bacteria. for example, piperacillin/tazobactam or ceftriaxone IV for 48 hours. ${ }^{177}$

\section{Blood products}

As INR is often inaccurate, thromboelastography (TEG) can inform whether FFP is required. Consider platelet transfusion if platelet count $<50 \times 10^{5}$. 


\section{Recommendations: preparation for TIPSS}

- All patients considered for elective TIPSS should be discussed in a multidisciplinary team, and be reviewed by both hepatology and interventional radiology in the clinical setting as part of the work-up (strong recommendation, very low level of evidence).

- Cross-sectional imaging is recommended prior to TIPSS where possible (strong recommendation, very low level of evidence).

- Informed consent should follow established principles (strong recommendation, high level of evidence).

- General anaesthetic or deep sedation using propofol is recommended for all procedures (strong recommendation, very low level of evidence).

- Routine prophylactic antibiotics are not recommended with the exception of TIPSS for variceal bleeding, complex procedures or where there is previous biliary instrumentation (strong recommendation, very low level of evidence).

- The decision to correct any coagulopathy should be based on thromboelastography since INR is often unreliable in liver disease (strong recommendation, moderate level of evidence). Platelet transfusion can be considered if platelet count $<50 \times 10^{5} / \mathrm{L}$ (weak recommendation, very low level of evidence).

\section{The TIPSS procedure}

\section{Equipment requirements}

Access to high-resolution, large field-of-view, flat panel detector with digital subtraction angiography.

$\mathrm{CO}_{2}$ angiography and $\mathrm{C}$-arm CT can be useful. A large angiography suite suitable for general anaesthesia and equipment for invasive pressure monitoring is required. Box 1 lists the standard equipment

\section{TIPSS technique}

A detailed description of the technique is beyond the scope of this guideline and can be found elsewhere. The key technical element of the procedure is the portal vein puncture. This may

\section{Box 1 Equipment required in the interventional} radiology suite

C-arm (preferably ceiling-mounted and capable of rotational cone-beam CT)

Large room suitable for general anaesthesia with piped anaesthetic gases and suction

Vital sign monitoring and display (ECG, pulse oximetry, invasive pressure monitoring)

$\mathrm{U} / \mathrm{S}$ (preferable integrated with the fluoroscopic unit)

TIPSS access sets

Range of appropriate stent grafts (covered stents should be used $8-10 \mathrm{~mm}$ diameter)

Angioplasty balloons 5-10 $\mathrm{mm}$ diameters (high-pressure

balloons desirable)

Embolisation equipment (vascular coils, plugs and liquid embolics such as cyanoacrylate glue)

Drainage catheters (for ascites and pleural effusions)

Range of angiographic catheters for pressure measurements, vessel access and subtraction angiography

Staff capable of invasive pressure monitoring and familiar with the equipment

CO2 angiography is not essential but would be desirable be facilitated by ultrasound guidance, which has been shown to reduce screen time. ${ }^{178}$ Stent placement should not compromise future options for transplantation, and should therefore not extend towards splenic/superior mesenteric vein confluence, as this disrupts surgical portal vein anastomosis. Stents placed near or in the right atrium will likewise seriously compromise the caval anastomosis. PTFE-covered stents have been shown to reduce the stenosis rate compared with bare stents, and are cost effective. ${ }^{179}$ TIPSS provides access to the splanchnic circulation, and allows variceal embolisation. The portal pressure gradient (PPG) is that between the portal pressure and IVC pressure, that is, porto-caval gradient. The porto-atrial gradient can give a false higher PPG and is affected by intraabdominal pressures. ${ }^{180}$

\section{Mitigation of encephalopathy during the TIPSS procedure}

Large-diameter portosystemic shunts are associated with a greater risk of HE, so logically a smaller diameter TIPSS stent will reduce that risk. Unfortunately, this also runs the risk of not achieving adequate portal pressure reduction. The concept was investigated in a RCT which compared $8 \mathrm{~mm}$ stents and $10 \mathrm{~mm}$ stents and was stopped early as the smaller stent diameter was associated with less control of complications of the portal hypertension. ${ }^{73}$ The introduction of controlled expansion stents (with a "dial-able" diameter of 8 or $10 \mathrm{~mm}$ ) may allow the operator to modulate the encephalopathy rate, but this is not evidence-based.

Allied to the shunt diameter as a determinant of encephalopathy, targeting post-TIPSS portosystemic gradient values of $<12 \mathrm{mmHg},{ }^{181}$ may result in the formation of very large shunts in patients with high portal pressure, and percentage reductions may be more practical (eg, 20\%). Indeed a proposed PSG of between 6 and $8 \mathrm{mmHg}$ in patients undergoing TIPSS for diuretic resistant ascites ${ }^{182}$ may be too low, especially in a group who exhibit more advanced liver disease, and who have a higher risk of encephalopathy.

\section{Adjunctive variceal/shunt embolisation}

Conceptually, placement of a TIPSS associated with competing shunt embolisation should preserve portal blood flow, and hence reduce HE. This can be as simple as embolising a bleeding varix to the placement of multiple occlusion devices in umbilical veins and splenorenal shunts. The evidence supporting this approach ab initio is conflicting ${ }^{26} 183184$ however, pre-TIPSS cross-sectional imaging review should allow procedural planning and encephalopathy mitigation if there is thought to be a significant risk.

\section{Post-operative care}

Post-operative right upper quadrant discomfort is common, and usually responds to parenteral paracetamol or opiate-based analgesia. Persistent severe pain, particularly when associated with haemodynamic compromise, warrants urgent investigation and contrast-enhanced CT is recommended.

Early Doppler US (within 7 days of implantation) is unreliable ${ }^{185}$ but confirmation of TIPSS flow prior to discharge is recommended in pro-thrombotic patients (eg, BCS and splanchnic vein thrombosis)

\section{Long-term follow up}

The majority of patients who undergo TIPSS will have cirrhosis, and Doppler studies may be performed at the time of routine 6-monthly HCC screening where offered. Routine transjugular venography is not required unless stent dysfunction is seen on Doppler studies, or clinically suspected (eg, recurrent ascites). 
Table 2

\begin{tabular}{lll}
\hline Complication & Classification & Definition \\
\hline Minor & Fever, haemobilia & No additional therapy and no prolonged in- patient care $<10 \%$ \\
Major & $\begin{array}{l}\text { Haemoperitoneum, biliary peritonitis, hepatic } \\
\text { infarction, trauma to hepatic artery or branches, } \\
\text { renal failure, liver failure, heart failure, TIPSS } \\
\text { infection (TIPSSitis) }\end{array}$ & $\begin{array}{l}\text { Requiring additional therapy and/or prolonged hospital } \\
\text { admission }\end{array}$ \\
\hline Death & & $<2 \%$ \\
\hline
\end{tabular}

Patients with BCS form a unique group due to their prothrombotic tendency and should have careful follow-up including routine TIPSS venography as determined by the interventional radiologist.

\section{Procedural complications}

Complications will partially depend on the case mix and the data in table 2 is related to uncomplicated TIPSS as above. ${ }^{175}$ It is established that complication rates and survival are related to the number of cases performed by the centre and operators independently. It is clear from published data and case series that gathering enough data locally to reach any kind of statistical significance over a short period of time is challenging $(<5$ years). The complication rates only act as a guide to help inform local or ideally networked outcomes. However, if a programme is failing to meet expected outcomes then a review of the service should take place.

\section{Recommendations: TIPSS procedure}

- All TIPSS should be performed using PTFE-covered stents as they are associated with better patency rates than bare stents (strong recommendation, high level of evidence).

- The portal pressure gradient should be measured as that between the portal pressure and IVC, and measured pre- and post-stent deployment (strong recommendation, moderate level of evidence).

- The portal pressure gradient should be reduced to $<12 \mathrm{mmHg}$ or by $>=20 \%$ of baseline in the case of variceal bleeding (strong recommendation, high level of evidence). For other indications, further reductions in the portal pressure gradient needs to balance efficacy with the risk of hepatic encephalopathy, and should be individualised (weak recommendation, low level of evidence).

- The role of embolisation with TIPSS is not clear and decisions should be individualised and based on cross-sectional imaging and portography showing large varices when portal pressure reduction alone may not be sufficient (weak recommendation, low level of evidence).

- A Doppler ultrasound is recommended a week after TIPSS implantation in patients with prothrombotic conditions, and in other patients where TIPSS dysfunction is suspected (strong recommendation, low level of evidence). Doppler ultrasound is recommended at 6-12 monthly intervals or 6-monthly in patients undergoing HCC surveillance (weak recommendation, low level of evidence).

- Patients with prothrombotic conditions such as BCS require follow-up with Doppler ultrasound with careful consideration for TIPSS venography as determined by the interventional radiologist. There is no indication for routine venography in other patients (strong recommendation, low level of evidence).

\section{SERVICE DELIVERY AND DEVELOPMENT}

\section{Service provision in the UK}

A detailed national audit using data from NHS England and utilising the metric of Finished Consultant Episodes (FCEs) and Finished Admission Episodes (FAEs) provides some important information in terms of service provision, and service planning. The definition of service provision is clearly vital and interpretation may vary from a $24 / 7$ service, a $7 / 7$ service, a 5/7 service or a $1 / 7$ service.

The majority of units that indicated they provided a TIPSS service performed 11-20 emergency procedures per year. Four units reported doing more than 30 emergency procedures per year. Additionally, there were units reporting a total number of procedures performed (elective and emergency) in a year of eight, raising the challenging question of numbers required for competency. A recent Canadian publication indicated that outcomes improved with units performing a minimum of 10 procedures per year. ${ }^{186}$ Furthermore, between 2006-2017, there was no clear evidence of an increase in emergency procedures, despite published evidence and recommendations. This may reflect a failure of clinical uptake, but may also reflect lack of capacity, ie, there is demand but not the ability to transfer patients in an emergency to a unit that has the available beds. Logically, each hospital should know who its TIPSS provider is, and each TIPSS provider should be equipped to deliver on that expectation.

\section{Personnel}

Each centre will need to staff according to the level of urgency they are prepared to undertake. TIPSS may be performed in emergency (uncontrolled variceal haemorrhage), urgent (eg, controlled but refractory variceal haemorrhage) and elective (eg, refractory ascites). table 3 lists the key personnel and their roles.

\section{Pathways and protocols}

All centres should have locally agreed guidelines and protocols in place and coordinated between the major stake holders. These should be reviewed on a regular basis in light of new and emerging data.

\section{M\&M and audit}

All participants in a TIPSS service should have arrangements, either locally or as part of a network, to submit data and outcomes to formal morbidity and mortality review and audit. These data should be measured against national data if available and be open to scrutiny.

\section{Benchmarking}

This should form an essential part of M\&M and audit. Agreed standards of practice are hard to judge given the small number of cases performed in most UK centres, and therefore 


\begin{tabular}{ll}
\hline Table 3 & Description \\
\hline Personnel & $\begin{array}{l}\text { At least two fully trained interventional radiologists or similarly-trained physicians able to carry out TIPSS } \\
\text { independently and other related procedures such as variceal embolisation. Forming viable networks would be } \\
\text { advised. Please see section on Networks (https://www.england.nhs.uk/wp-content/uploads/2012/11/scn-sof.pdf) } \\
\text { Interventional radiologists } \\
\text { Hepatology team used to caring for patients with portal hypertension and its major complications (variceal } \\
\text { haemorrhage, ascites and encephalopathy etc) }\end{array}$ \\
$\begin{array}{ll}\text { Intensivists used to care for patients with portal hypertension and variceal haemorrhage. } \\
\text { Intensive care }\end{array}$ & $\begin{array}{l}\text { Anaesthetists who are used to working in Interventional radiology suites and are used to dealing with patients } \\
\text { who may have the complications of portal hypertension (pleural effusions, heart failure, encephalopathy, variceal } \\
\text { haemorrhage etc). }\end{array}$ \\
\hline Key support staff & $\begin{array}{l}\text { Fully trained interventional support staff including nurses (capable of invasive pressure measurements) and } \\
\text { radiographers }\end{array}$ \\
Other disciplines as necessary & $\begin{array}{l}\text { Nephrology with access to renal replacement therapy. } \\
\text { Microbiology. } \\
\text { Cardiology assessment. } \\
\text { Liver transplant services (These will not always be locally available but networked communication channels should } \\
\text { be clearly defined) } \\
\text { Addiction services with pathways clearly defined. }\end{array}$ \\
\hline
\end{tabular}

submission of data to a national registry to help inform future planning and benchmarking would be ideal (as yet none exist). The figures quoted in table 4 are a guide and consideration has to be given to the case mix and severity of liver disease being treated. ${ }^{175}$

Suggested outcomes for uncomplicated TIPSS (ie, no portal vein thrombosis and patent hepatic veins) is given in table 4.

For complex TIPSS (thrombosed portal or hepatic veins, or previous transplant) it is recommended that these are performed in centres with $>20$ cases per annum and given the small numbers of outcome data and benchmarking, is difficult. ${ }^{187}$ Further evidence supports the need to ensure that centres wishing to start a TIPSS perform at least 10 procedures a year, regardless of whether the centre is a teaching hospital or not. ${ }^{186}$

\section{Recommendations: service delivery and development}

- Units offering a TIPSS service should be performing a minimum of 10 cases per annum (strong recommendation, moderate quality of evidence).

- It is recommended that centres offering complex TIPSS (thrombosed hepatic or portal veins or in transplant recipients) should perform at least 20 cases per annum (strong recommendation, moderate quality of evidence).

- Patients being referred for emergency TIPSS should be prioritised for transfer (strong recommendation, low quality of evidence).

\section{Research recommendations}

- The role of early or pre-emptive TIPSS in acute variceal bleeding in view of the conflicting evidence and uncertainly about patient selection. Large multi-centre RCTs would be the gold standard.

\begin{tabular}{llc}
\hline Table 4 & & \\
\hline & Measure & Outcome \\
\hline Technical success & $\begin{array}{l}\text { Creation of a connection between the IVC and } \\
\text { portal vein with a stent graft }\end{array}$ & $>90 \%$ \\
Haemodynamic & Target reduction of porto-systemic gradient & $>90 \%$ \\
Clinical success & No further variceal bleeding & $90 \%$ \\
& Resolution of ascites & $55 \%$ \\
\hline
\end{tabular}

- The role of TIPSS as first-line therapy in secondary prevention against variceal rebleeding.

- A national registry or database to help inform us about the results in a variety of indications and evaluate current service provision.

- Nutrition in patients undergoing TIPSS. Patients' nutrition can significantly improve following TIPSS for ascites but sarcopenia may be associated with more encephalopathy.

- TIPSS in the setting of chronic renal impairment and hepatorenal syndrome.

- Cardiac evaluation prior to TIPSS due to the limitations of the present methods. The role of NT-proBNP is not clear.

- Haemodynamic goals following TIPSS. Further study around the ideal reduction of portal pressure gradient both for variceal haemorrhage and the treatment of refractory ascites.

- The role of TIPSS in hepatic hydrothorax, and further study comparing TIPSS with standard of care is recommended.

- The role of prophylactic TIPSS prior to major non-hepatic surgery due to a lack of good quality data on whether it improves outcome.

- Role of TIPSS in patients with ectopic varices to allow access to the portal system as well as reducing portal pressure.

\section{Author affiliations}

${ }^{1}$ Liver Unit, University Hospitals Birmingham NHS Foundation Trust, Birmingham, UK ${ }^{2}$ Institute of Immunology and Immunotherapy, University of Birmingham,

Birmingham, UK

${ }^{3} \mathrm{NIHR}$ Birmingham Biomedical Research Centre, University Hospitals Birmingham NHS Foundation Trust and University of Birmingham, Birmingham, UK

${ }^{4}$ Gastroenterology Department, Glasgow Royal Infirmary, Glasgow, UK

${ }^{5}$ Hepatology Department, Royal Infirmary of Edinburgh, Edinburgh, UK

${ }^{6}$ Department if Radiology, Queen's Medical Centre Nottingham University Hospital NHS Trust, Nottingham, UK

${ }^{7}$ The Royal Free Sheila Sherlock Liver Centre, UCL Institute for Liver and Digestive Health, London, UK

${ }^{8}$ University of Leeds, Leeds, UK

${ }^{9}$ London, UK

${ }^{10}$ Department of Radiology, Royal Infirmary of Edinburgh, Edinburgh, UK

${ }^{11}$ Walton on Thames, UK

${ }^{12}$ Liver Unit, Cambridge University Hospitals NHS Foundation Trust, Cambridge, UK

${ }^{13}$ Department of Radiology, University Hospitals Birmingham NHS Foundation Trust, Birmingham, UK

${ }^{14}$ Department of Hepatology, Portsmouth Hospitals NHS Trust, Portsmouth, UK

Twitter Dhiraj Tripathi @dtrip2015 and lan A Rowe @lanARowe 
Acknowledgements We wish to thank the BSG Liver Section for support and internal review of the guideline. We are grateful to BSIR and BASL for review and endorsement of this guideline.

Collaborators British Society of Gastroenterology (BSG). British Society of Interventional Radiology (BSIR). British Association for the Study of the Liver (BASL).

Contributors Dr David Patch: chair of GDG and senior author. Dr Dhiraj Tripathi: co-author (all sections), BSG Liver Section Representative. Professor Adrian Stanley: co-author (TIPSS for ascites). Professor Peter Hayes: co-author (TIPSS for variceal bleeding and research recommendations). Dr Emmanuel Tsochatzis: co-author (TIPSS for ascites). Dr lan Rowe: co-author (TIPSS for hepatic hydrothorax). Dr Matthew Armstrong: co-author (cardiac assessment, nutritional assessment). Dr Richard Aspinall: reviewer, BSG Liver Section Representative. Dr Joanna Leithead: co-author (TIPSS for hepatorenal syndrome). Dr Simon Travis: co-author (procedural details, service delivery and development). Dr Homoyon Mehrzad: reviewer. Dr Hamish Ireland: co-author (procedural details, service delivery and development).Sister Joanne McDonagh: reviewer. Mandy Lomax: co-author (patient summary). Nicholas Roslund: co-author (patient summary). All authors reviewed and approved the final document.

Funding The authors have not declared a specific grant for this research from any funding agency in the public, commercial or not-for-profit sectors.

Competing interests Dr David Patch: contribution to charity-administered educational fund for teaching purposes (Cook Medical). Dr Dhiraj Tripathi: educational funding (Gore Ltd). Chief investigator of CALIBRE trial investigating non-selective beta-blockers versus variceal band ligation in variceal bleeding (NIHR HTA funding). Member of National Institute of Health and Care Excellence (NICE) Interventional Procedures Advisory Committee (IPAC). Dr Homoyon Mehrzad: speaker fees (Gore Ltd) and educational funding (Gore Ltd). Professor Peter Hayes: speaker fees (Gore Medical). Dr Simon Travis: educational donations for sponsorship to attend scientific meetings and fund courses to train on specific equipment (Abbott Medical, Gore Ltd, Boston Scientific). Dr Richard Aspinall: trustee to charity Liver4Life. Other authors have not declared any conflicts of interest.

\section{Patient consent for publication Not required.}

Provenance and peer review Not commissioned; externally peer reviewed. Data availability statement All data relevant to the study are included in the article.

Open access This is an open access article distributed in accordance with the Creative Commons Attribution Non Commercial (CC BY-NC 4.0) license, which permits others to distribute, remix, adapt, build upon this work non-commercially, and license their derivative works on different terms, provided the original work is properly cited, appropriate credit is given, any changes made indicated, and the use is non-commercial. See: http://creativecommons.org/licenses/by-nc/4.0/.

\section{ORCID iDs}

Dhiraj Tripathi http://orcid.org/0000-0001-9043-6382

Adrian J Stanley http://orcid.org/0000-0002-9761-9795

Peter C Hayes http://orcid.org/0000-0002-9660-8322

Matthew J Armstrong http://orcid.org/0000-0002-3425-1161

Emmanuel A Tsochatzis http://orcid.org/0000-0001-5069-2461

Ian A Rowe http://orcid.org/0000-0003-1288-0749

Hamish Ireland http://orcid.org/0000-0001-6740-7145

Richard J Aspinall http://orcid.org/0000-0002-5208-8185

\section{REFERENCES}

1 Thabut D, Pauwels A, Carbonell N, et al. Cirrhotic patients with portal hypertensionrelated bleeding and an indication for early tips: a large multicentre audit with real-life results. J Hepatol 2017;68:73-81.

2 Bissonnette J, Garcia-Pagán JC, Albillos A, et al. Role of the transjugular intrahepatic portosystemic shunt in the management of severe complications of portal hypertension in idiopathic noncirrhotic portal hypertension. Hepatology 2016;64:224-31

3 Lahat E, Lim C, Bhangui P, et al. Transjugular intrahepatic portosystemic shunt as a bridge to non-hepatic surgery in cirrhotic patients with severe portal hypertension: a systematic review. HPB 2018;20:101-9.

4 Tripathi D, MacNicholas R, Kothari C, et al. Good clinical outcomes following transjugular intrahepatic portosystemic stent-shunts in Budd-Chiari syndrome. Aliment Pharmacol Ther 2014;39:864-72.

5 Brouwers MC, Kho ME, Browman GP, et al. Agree Il: advancing guideline development, reporting and evaluation in health care. Can Med Assoc J 2010;182:E839-42.

6 Fagiuoli S, Bruno R, Debernardi Venon W, et al. Consensus conference on TIPS management: techniques, indications, contraindications. Digestive and Liver Disease 2017:49:121-37
7 Neumann I, Santesso N, AkI EA, et al. A guide for health professionals to interpret and use recommendations in guidelines developed with the grade approach. J Clin Epidemiol 2016;72:45-55.

8 Rösch J, Hanafee WN, Snow H. Transjugular portal venography and radiologic portacaval shunt: an experimental study. Radiology 1969;92:1112-4.

9 Rösch J, Hanafee W, Snow H, et al. Transjugular intrahepatic portacaval shunt: an experimental work. Am J Surg 1971;121:588-92.

10 Reich M, Olumide F, Jorgensen E, et al. Experimental cryoprobe production of intrahepatic portocaval shunt. J Surg Res 1977;23:14-18

11 Colapinto RF, Stronell RD, Birch SJ, et al. Creation of an intrahepatic portosystemic shunt with a Grüntzig balloon catheter. Can Med Assoc J 1982;126:267-8.

12 Palmaz JC, Sibbitt RR, Reuter SR, et al. Expandable intrahepatic portacaval shunt stents: early experience in the dog. AJR Am J Roentgenol 1985;145:821-5.

13 Richter GM, Palmaz JC, Nöldge G, et al. [The transjugular intrahepatic portosystemic stent-shunt. A new nonsurgical percutaneous method]. Radiologe 1989;29:406-11.

14 Bureau C, Garcia Pagan JC, Layrargues GP, et al. Patency of stents covered with polytetrafluoroethylene in patients treated by transjugular intrahepatic portosystemic shunts: long-term results of a randomized multicentre study. Liver Int 2007:27:742-7.

15 Azoulay D, Castaing D, Majno P, et al. Salvage transjugular intrahepatic portosystemic shunt for uncontrolled variceal bleeding in patients with decompensated cirrhosis. J Hepatol 2001;35:590-7

16 Vangeli M, Patch D, Burroughs AK. Salvage tips for uncontrolled variceal bleeding. J Hepatol 2002;37:703-4

17 Barange K, Péron J-M, Imani K, et al. Transjugular intrahepatic portosystemic shunt in the treatment of refractory bleeding from ruptured gastric varices. Hepatology 1999;30:1139-43

18 Maimone S, Saffioti F, Filomia R, et al. Predictors of re-bleeding and mortality among patients with refractory variceal bleeding undergoing salvage transjugular intrahepatic portosystemic shunt (tips). Dig Dis Sci 2019;64:1335-45.

19 Zhang H, Zhang H, Li H, et al. Tips versus endoscopic therapy for variceal rebleeding in cirrhosis: a meta-analysis update. J Huazhong Univ Sci Technolog Med Sci 2017;37:475-85.

20 Sauerbruch T, Mengel M, Dollinger M, et al. Prevention of rebleeding from esophageal varices in patients with cirrhosis receiving small-diameter stents versus hemodynamically controlled medical therapy. Gastroenterology 2015;149:660-8.

21 Holster IL, Tjwa ETTL, Moelker A, et al. Covered transjugular intrahepatic portosystemic shunt versus endoscopic therapy $+\beta$-blocker for prevention of variceal rebleeding. Hepatology 2016;63:581-9.

22 Lv Y, Qi X, He C, et al. Covered tips versus endoscopic band ligation plus propranolol for the prevention of variceal rebleeding in cirrhotic patients with portal vein thrombosis: a randomised controlled trial. Gut 2018;67:2156-68.

23 Qi X, Tian Y, Zhang W, et al. Covered tips for secondary prophylaxis of variceal bleeding in liver cirrhosis: a systematic review and meta-analysis of randomized controlled trials. Medicine 2016;95:e5680.

24 Rössle M, Schultheiss M. Commentary on "Covered TIPS for secondary prophylaxis of variceal bleeding in liver cirrhosis: a systematic review and meta-analysis of randomized controlled trials". AME Med J 2017;2:33.

25 Lo G-H, Liang H-L, Chen W-C, et al. A prospective, randomized controlled trial of transjugular intrahepatic portosystemic shunt versus cyanoacrylate injection in the prevention of gastric variceal rebleeding. Endoscopy 2007;39:679-85.

26 Qi X, Liu L, Bai M, et al. Transjugular intrahepatic portosystemic shunt in combination with or without variceal embolization for the prevention of variceal rebleeding: a meta-analysis. J Gastroenterol Hepatol 2014;29:688-96.

27 Monescillo A, Martnez-Lagares F, Ruiz-del-Arbol L, et al. Influence of portal hypertension and its early decompression by tips placement on the outcome of variceal bleeding. Hepatology 2004;40:793-801.

28 García-Pagán JC, Caca K, Bureau C, et al. Early use of tips in patients with cirrhosis and variceal bleeding. N Engl J Med 2010;362:2370-9.

29 Garcia-Pagán JC, Di Pascoli M, Caca K, et al. Use of early-TIPS for high-risk variceal bleeding: results of a post-RCT surveillance study. J Hepatol 2013;58:45-50.

30 Lv Y, Yang Z, Liu L, et al. Early tips with covered stents versus standard treatment for acute variceal bleeding in patients with advanced cirrhosis: a randomised controlled trial. Lancet Gastroenterol Hepatol 2019;4:587-98.

31 Tripathi D, Stanley AJ, Hayes PC, et al. Uk guidelines on the management of variceal haemorrhage in cirrhotic patients. Gut 2015:64:1680-704.

32 de Franchis R, Baveno VIF. Expanding consensus in portal hypertension: report of the Baveno $\mathrm{VI}$ consensus workshop: stratifying risk and individualizing care for portal hypertension. J Hepatol 2015;63:743-52.

33 Dunne P, Sinha R, Stanley A, et al. OTU-09 use of early-TIPSS in patients with oesophageal variceal bleeding, a UK dual-centre randomised control trial. Gut 2019:68:A105-6

34 Njei B, McCarty TR, Laine L. Early transjugular intrahepatic portosystemic shunt in US patients hospitalized with acute esophageal variceal bleeding. J Gastroenterol Hepatol 2017:32:852-8.

35 Rudler M, Cluzel P, Corvec TL, et al. Early-TIPSS placement prevents rebleeding in high-risk patients with variceal bleeding, without improving survival. Aliment Pharmacol Ther 2014;40:1074-80. 
36 Deltenre P, Trepo E, Rudler M, et al. Early transjugular intrahepatic portosystemic shunt in cirrhotic patients with acute variceal bleeding: a systematic review and meta-analysis of controlled trials. Eur J Gastroenterol Hepatol 2015;27:e1-9.

37 Hernández-Gea V, Procopet B, Giráldez Álvaro, et al. Preemptive-TIPS improves outcome in high-risk variceal bleeding: an observational study. Hepatology 2019:69:282-93.

38 Conejo I, Guardascione MA, Tandon P, et al. Multicenter external validation of risk stratification criteria for patients with variceal bleeding. Clin Gastroenterol Hepatol 2018;16:132-9.

39 Lv Y, Zuo L, Zhu X, et al. Identifying optimal candidates for early tips among patients with cirrhosis and acute variceal bleeding: a multicentre observational study. Gut 2019:68:1297-310.

40 Kochar N, Tripathi D, McAvoy NC, et al. Bleeding ectopic varices in cirrhosis: the role of transjugular intrahepatic portosystemic stent shunts. Aliment Pharmacol Ther 2008:28:294-303.

41 Vidal V, Joly L, Perreault P, et al. Usefulness of transjugular intrahepatic portosystemic shunt in the management of bleeding ectopic varices in cirrhotic patients. Cardiovasc Intervent Radiol 2006;29:216-9.

42 Nayar M, Saravanan R, Rowlands PC, et al. TIPSS in the treatment of ectopic variceal bleeding. Hepatogastroenterology 2006;53:584-7.

43 Vangeli M, Patch D, Terreni N, et al. Bleeding ectopic varices - treatment with transjugular intrahepatic porto-systemic shunt (tips) and embolisation. J Hepatol 2004:41:560-6.

44 Shibata D, Brophy DP, Gordon FD, et al. Transjugular intrahepatic portosystemic shunt for treatment of bleeding ectopic varices with portal hypertension. Diseases Colon Rectum 1999:42:1581-5.

45 Oey RC, de Wit K, Moelker A, et al. Variable efficacy of TIPSS in the management of ectopic variceal bleeding: a multicentre retrospective study. Aliment Pharmacol Ther 2018;48:975-83

46 Ashraf P, Shah GM, Shaikh H, et al. Transjugular intrahepatic portosystemic stenting in portal hypertensive gastropathy. J Coll Physicians Surg Pak 2009;19:584-5.

47 Mezawa S, Homma H, Ohta H, et al. Effect of transjugular intrahepatic portosystemic shunt formation on portal hypertensive gastropathy and gastric circulation. Am J Gastroenterol 2001;96:1155-9.

48 Urata J, Yamashita Y, Tsuchigame T, et al. The effects of transjugular intrahepatic portosystemic shunt on portal hypertensive gastropathy. J Gastroenterol Hepatol 1998;13:1061-7.

49 European Association for the Study of the Liver. Electronic address: easloffice@ easloffice.eu, European Association for the Study of the Liver. EASL clinical practice guidelines for the management of patients with decompensated cirrhosis. $J$ Hepatol 2018:69:406-60.

50 Gjeorgjievski M, Cappell MS. Portal hypertensive gastropathy: a systematic review of the pathophysiology, clinical presentation, natural history and therapy. World J Hepatol 2016;8:231-62

51 Hsu W-H, Wang Y-K, Hsieh M-S, et al. Insights into the management of gastric antral vascular ectasia (watermelon stomach). Therap Adv Gastroenterol 2018; 11:1756283X17747471.

52 Ghobrial C, Rabea M, Mohsen N, et al. Gastric antral vascular ectasia in portal hypertensive children: endoscopic band ligation versus argon plasma coagulation. $J$ Pediatr Surg 2019;54:1691-5.

53 McCarty TR, Rustagi T. Comparative effectiveness and safety of radiofrequency ablation versus argon plasma coagulation for treatment of gastric antral vascular ectasia. J Clin Gastroenterol 2019;53:599-606.

54 Lebrec D, Giuily N, Hadengue A, et al. Transjugular intrahepatic portosystemic shunts: comparison with paracentesis in patients with cirrhosis and refractory ascites: a randomized trial. French group of clinicians and a group of biologists. J Hepatol 1996:25:135-44.

55 Rössle M, Ochs A, Gülberg V, et al. A comparison of paracentesis and transjugular intrahepatic portosystemic shunting in patients with ascites. $N$ Engl J Med 2000;342:1701-7.

56 Ginès P, Uriz J, Calahorra B, et al. Transjugular intrahepatic portosystemic shunting versus paracentesis plus albumin for refractory ascites in cirrhosis. Gastroenterology 2002:123:1839-47.

57 Sanyal AJ, Genning C, Reddy KR, et al. The North American study for the treatment of refractory ascites. Gastroenterology 2003;124:634-41.

58 Salerno F, Merli M, Riggio 0, et al. Randomized controlled study of tips versus paracentesis plus albumin in cirrhosis with severe ascites. Hepatology 2004:40:629-35.

59 Bureau C, Thabut D, Oberti F, et al. Transjugular intrahepatic portosystemic shunts with covered stents increase transplant-free survival of patients with cirrhosis and recurrent ascites. Gastroenterology 2017;152:157-63.

60 Narahara Y, Kanazawa H, Fukuda T, et al. Transjugular intrahepatic portosystemic shunt versus paracentesis plus albumin in patients with refractory ascites who have good hepatic and renal function: a prospective randomized trial. J Gastroenterol 2011:46:78-85.

61 Albillos A, Bañares R, González M, et al. A meta-analysis of transjugular intrahepatic portosystemic shunt versus paracentesis for refractory ascites. J Hepatol 2005;43:990-6.
62 Bai Met al. Tips improves liver transplantation-free survival in cirrhotic patients with refractory ascites: an updated meta-analysis. WJG 2014;20:2704-14.

63 Chen RP, Zhu Ge XJ, Huang ZM, et al. Prophylactic use of transjugular intrahepatic portosystemic shunt AIDS in the treatment of refractory ascites: metaregression and trial sequential meta-analysis. J Clin Gastroenterol 2014;48:290-9.

64 D’Amico G, Luca A, Morabito A, et al. Uncovered transjugular intrahepatic portosystemic shunt for refractory ascites: a meta-analysis. Gastroenterology 2005; 129:1282-93.

65 Deltenre P, Mathurin P, Dharancy S, et al. Transjugular intrahepatic portosystemic shunt in refractory ascites: a meta-analysis. Liver Int 2005;25:349-56.

66 Saab S, Nieto JM, Lewis SK, et al. Tips versus paracentesis for cirrhotic patients with refractory ascites. Cochrane Database Syst Rev 2006:Cd004889.

67 Salerno F, Cammà C, Enea M, et al. Transjugular intrahepatic portosystemic shunt for refractory ascites: a meta-analysis of individual patient data. Gastroenterology 2007:133:825-34.

68 NICE. Cirrhosis in over 16S: assessment and management. London: NICE, 2016.

69 Maleux G, Perez-Gutierrez NA, Evrard S, et al. Covered stents are better than uncovered stents for transjugular intrahepatic portosystemic shunts in cirrhotic patients with refractory ascites: a retrospective cohort study. Acta Gastroenterol Be/g 2010:73:336-41.

70 Tan HK, James PD, Sniderman KW, et al. Long-term clinical outcome of patients with cirrhosis and refractory ascites treated with transjugular intrahepatic portosystemic shunt insertion. J Gastroenterol Hepatol 2015;30:389-95.

71 Gaba RC, Parvinian A, Casadaban LC, et al. Survival benefit of tips versus serial paracentesis in patients with refractory ascites: a single institution case-control propensity score analysis. Clin Radiol 2015;70:e51-7.

72 Wang Q, Lv Y, Bai M, et al. Eight millimetre covered tips does not compromise shunt function but reduces hepatic encephalopathy in preventing variceal rebleeding. $J$ Hepatol 2017;67:508-16.

73 Riggio 0, Ridola L, Angeloni S, et al. Clinical efficacy of transjugular intrahepatic portosystemic shunt created with covered stents with different diameters: results of a randomized controlled trial. J Hepatol 2010;53:267-72.

74 Miraglia R, Maruzzelli L, Tuzzolino F, et al. Transjugular intrahepatic portosystemic shunts in patients with cirrhosis with refractory ascites: comparison of clinical outcomes by using 8- and 10-mm PTFE-covered stents. Radiology 2017;284:281-8.

75 Trebicka J, Bastgen D, Byrtus J, et al. Smaller-diameter covered transjugular intrahepatic portosystemic shunt stents are associated with increased survival. LID S1542-3565(19)30352-0 [pii] LID.

76 Kamath Pet al. A model to predict survival in patients with end-stage liver disease. Hepatology 2001;33:464-70.

77 Malinchoc M, Kamath PS, Gordon FD, et al. A model to predict poor survival in patients undergoing transjugular intrahepatic portosystemic shunts. Hepatology 2000:31:864-71.

78 Salerno F, Guevara M, Bernardi M, et al. Refractory ascites: pathogenesis, definition and therapy of a severe complication in patients with cirrhosis. Liver Int 2010;30:937-47

79 Gaba RC, Couture PM, Bui JT, et al. Prognostic capability of different liver disease scoring systems for prediction of early mortality after transjugular intrahepatic portosystemic shunt creation. J Vasc Interv Radiol 2013:24:411-20.

80 Bureau C, Métivier S, D'Amico M, et al. Serum bilirubin and platelet count: a simple predictive model for survival in patients with refractory ascites treated by tips. J Hepatol 2011;54:901-7.

81 Krowka MJ, Wiesner RH, Heimbach JK. Pulmonary contraindications, indications and MELD exceptions for liver transplantation: a contemporary view and look forward. J Hepatol 2013;59:367-74.

82 Dhanasekaran R, West JK, Gonzales PC, et al. Transjugular intrahepatic portosystemic shunt for symptomatic refractory hepatic hydrothorax in patients with cirrhosis. Am J Gastroenterol 2010;105:635-41.

83 Gordon FD, Anastopoulos HT, Crenshaw W, et al. The successful treatment of symptomatic, refractory hepatic hydrothorax with transjugular intrahepatic portosystemic shunt. Hepatology 1997;25:1366-9.

84 Jeffries MA, Kazanjian S, Wilson M, et al. Transjugular intrahepatic portosystemic shunts and liver transplantation in patients with refractory hepatic hydrothorax. Live Transp/ 1998:4:416-23.

85 Siegerstetter $\mathrm{V}$, Deibert $\mathrm{P}$, Ochs A, et al. Treatment of refractory hepatic hydrothorax with transjugular intrahepatic portosystemic shunt: long-term results in 40 patients. Eur J Gastroenterol Hepatol 2001:13:529-34.

86 Spencer EB, Cohen DT, Darcy MD. Safety and efficacy of transjugular intrahepatic portosystemic shunt creation for the treatment of hepatic hydrothorax. J Vasc Interv Radiol 2002;13:385-90.

87 Wilputte JY, Goffette P, Zech F, et al. The outcome after transjugular intrahepatic portosystemic shunt (tips) for hepatic hydrothorax is closely related to liver dysfunction: a long-term study in 28 patients. Acta Gastroenterologica Belgica 2007:70:6-10.

88 Ditah ICet al. Transjugular intrahepatic portosystemic stent shunt for medically refractory hepatic hydrothorax: a systematic review and cumulative meta-analysis. World J Hepatol 2015;7:1797-806. 
89 Brensing KAet al. Long term outcome after transjugular intrahepatic portosystemic stent-shunt in non-transplant cirrhotics with hepatorenal syndrome: a phase II study. Gut 2000;47:288-95.

90 Guevara M, Ginès P, Fernández-Esparrach G, et al. Reversibility of hepatorenal syndrome by prolonged administration of ornipressin and plasma volume expansion. Hepatology 1998;27:35-41.

91 Song T, Rössle M, He F, et al. Transjugular intrahepatic portosystemic shunt for hepatorenal syndrome: a systematic review and meta-analysis. Digestive and Liver Disease 2018;50:323-30.

92 European Association for the Study of the Liver. Electronic address: easloffice@ easloffice.eu. EASL clinical practice guidelines: vascular diseases of the liver. J Hepatol 2016:64:179-202.

93 Tripathi D, Sunderraj L, Vemala V, et al. Long-term outcomes following percutaneous hepatic vein recanalization for Budd-Chiari syndrome. Liver Int 2017;37:111-20.

94 He F, Zhao H, Dai S, et al. Transjugular intrahepatic portosystemic shunt for BuddChiari syndrome with diffuse occlusion of hepatic veins. Sci Rep 2016;6:36380.

95 Qi X, Guo W, He C, et al. Transjugular intrahepatic portosystemic shunt for BuddChiari syndrome: techniques, indications and results on 51 Chinese patients from a single centre. Liver Int 2014;34:1164-75.

96 Garcia-Pagán JC, Heydtmann M, Raffa S, et al. Tips for Budd-Chiari syndrome: long-term results and prognostics factors in 124 patients. Gastroenterology 2008;135:808-15.

97 Hayek G, Ronot M, Plessier A, et al. Long-term outcome and analysis of dysfunction of transjugular intrahepatic portosystemic shunt placement in chronic primary BuddChiari syndrome. Radiology 2017;283:280-92.

98 Neumann ABet al. Treatment of Budd-Chiari syndrome with a focus on transjugular intrahepatic portosystemic shunt. World J Hepatol 2013;5:38-42.

99 Pallidini I, Barbosa F, Monzio Compagnoni N, et al. Transjugular intrahepatic portosystemic shunt (tips) in the treatment of patients with symptomatic BuddChiari syndrome: patency assessment, overall survival, and long-term results (Abstract). CardioVascular and Interventional Radiology 2017;40:P696.

100 Rathod K, Deshmukh H, Shukla A, et al. Endovascular treatment of Budd-Chiari syndrome: single center experience. J Gastroenterol Hepatol 2017;32:237-43.

101 Rössle M, Olschewski M, Siegerstetter V, et al. The Budd-Chiari syndrome: outcome after treatment with the transjugular intrahepatic portosystemic shunt. Surgery 2004:135:394-403.

102 Seijo S, Plessier A, Hoekstra J, et al. Good long-term outcome of Budd-Chiari syndrome with a step-wise management. Hepatology 2013;57:1962-8.

103 Gamanagatti SR, Patel AH, et al. Long-term outcomes of transjugular intrahepatic portosystemic shunt in Indian patients with Budd-Chiari syndrome. Eur J Gastroenterol Hepatol 2017;29:1174-82.

104 Spiliopoulos S, Lalenis C, Konstantos C, et al. Long-term efficacy of transjugular intrahepatic portosystemic shunt treatment for Budd-Chiari syndrome 2017.

105 Mukund A, Mittal K, Mondal A, et al. Anatomic recanalization of hepatic vein and inferior vena cava versus direct intrahepatic portosystemic shunt creation in BuddChiari syndrome: overall outcome and midterm transplant-free survival. Journal of Vascular and Interventional Radiology 2018;29:790-9.

106 Montano-Loza AJ, Tandon P, Kneteman N, et al. Rotterdam score predicts early mortality in Budd-Chiari syndrome, and surgical shunting prolongs transplant-free survival. Aliment Pharmacol Ther 2009;30:1060-9.

107 Potthoff A, Attia D, Pischke S, et al. Long-Term outcome of liver transplant patients with Budd-Chiari syndrome secondary to myeloproliferative neoplasms. Liver Int 2015:35:2042-9.

108 Khan F, Armstrong MJ, Mehrzad H, et al. Review article: a multidisciplinary approach to the diagnosis and management of Budd-Chiari syndrome. Aliment Pharmacol Ther 2019;49:840-63.

109 Tabchouri N, Barbier L, Menahem B, et al. Original study: transjugular intrahepatic portosystemic shunt as a bridge to abdominal surgery in cirrhotic patients. J Gastrointest Surg 2019;23:2383-90.

110 Elkrief L, Ferrusquia-Acosta J, Payancé $A$, et al. Abdominal surgery in patients with idiopathic noncirrhotic portal hypertension: a multicenter retrospective study. Hepatology 2019;70:911-24.

111 Reverter E, Cirera I, Albillos A, et al. The prognostic role of hepatic venous pressure gradient in cirrhotic patients undergoing elective extrahepatic surgery. J Hepatol 2019;71:942-50

112 Northup PG, Friedman LS, Kamath PS. AGA Clinical Practice Update on Surgical Risk Assessment and Perioperative Management in Cirrhosis: Expert Review. Clinical Gastroenterology and Hepatology 2019;17:595-606.

113 De Gottardi A, Rautou P-E, Schouten J, et al. Porto-sinusoidal vascular disease: proposal and description of a novel entity. Lancet Gastroenterology \& Hepatology 2019:4:399-411.

114 Schouten JNL, Garcia-Pagan JC, Valla DC, et al. Idiopathic noncirrhotic portal hypertension. Hepatology 2011;54:1071-81.

115 Eapen CE, Nightingale P, Hubscher SG, et al. Non-cirrhotic intrahepatic portal hypertension: associated gut diseases and prognostic factors. Dig Dis $\mathrm{SCi}$ 2011;56:227-35
116 Schouten JNL, Nevens F, Hansen B, et al. Idiopathic noncirrhotic portal hypertension is associated with poor survival: results of a long-term cohort study. Aliment Pharmacol Ther 2012;35:1424-33.

117 Siramolpiwat S, Seijo S, Miquel R, et al. Idiopathic portal hypertension: natural history and long-term outcome. Hepatology 2014;59:2276-85.

118 Regnault D, d'Alteroche L, Nicolas C, et al. Ten-year experience of transjugular intrahepatic portosystemic shunt for noncirrhotic portal hypertension. Eur J Gastroenterol Hepatol 2018;30:557-62.

119 Lv Y, Li K, He C, et al. TIPSS for variceal bleeding in patients with idiopathic noncirrhotic portal hypertension: comparison with patients who have cirrhosis. Aliment Pharmacol Ther 2019:49:926-39.

120 Radosevich PM, Ring EJ, LaBerge JM, et al. Transjugular intrahepatic portosystemic shunts in patients with portal vein occlusion. Radiology 1993;186:523-7.

121 Klinger C, Riecken B, Schmidt A, et al. Transjugular local thrombolysis with/without tips in patients with acute non-cirrhotic, non-malignant portal vein thrombosis. Digestive Liver Disease 2017:49:1345-52.

122 Qi X, He C, Guo W, et al. Transjugular intrahepatic portosystemic shunt for portal vein thrombosis with variceal bleeding in liver cirrhosis: outcomes and predictors in a prospective cohort study. Liver Int 2016;36:667-76.

123 Thornburg B, Desai K, Hickey R, et al. Pretransplantation portal vein recanalization and transjugular intrahepatic portosystemic shunt creation for chronic portal vein thrombosis: final analysis of a 61-Patient cohort. J Vasc Intervent Radiology 2017;28:1714-21.

124 Senzolo M, Tibbals J, Cholongitas E, et al. Transjugular intrahepatic portosystemic shunt for portal vein thrombosis with and without cavernous transformation. Aliment Pharmacol Ther 2006;23:767-75.

125 Yerdel MA, Gunson B, Mirza D, et al. Portal vein thrombosis in adults undergoing liver transplantation: risk factors, screening, management, and outcome. Transplantation 2000;69:1873-81.

126 Sarin SK, Philips CA, Kamath PS, et al. Toward a comprehensive new classification of portal vein thrombosis in patients with cirrhosis. Gastroenterology 2016;151:574-7.

127 Valentin N, Korrapati P, Constantino J, et al. The role of transjugular intrahepatic portosystemic shunt in the management of portal vein thrombosis: a systematic review and meta-analysis. Eur J Gastroenterol Hepatol 2018;30:1187-93.

128 Rodrigues SG, Sixt S, Abraldes JG, et al. Systematic review with meta-analysis: portal vein recanalisation and transjugular intrahepatic portosystemic shunt for portal vein thrombosis. Aliment Pharmacol Ther 2019:49:20-30.

129 Habib A, Desai K, Hickey R, et al. Portal vein recanalization - transjugular intrahepatic portosystemic shunt using the transsplenic approach to achieve transplant candidacy in patients with chronic portal vein thrombosis. J Vasc Interventi Radiology 2015;26:499-506.

130 Blum U, Haag K, Rössle M, et al. Noncavernomatous portal vein thrombosis in hepatic cirrhosis: treatment with transjugular intrahepatic portosystemic shunt and local thrombolysis. Radiology 1995;195:153-7.

131 Bai M, Qi X, Yang Z, et al. Predictors of hepatic encephalopathy after transjugular intrahepatic portosystemic shunt in cirrhotic patients: a systematic review. J Gastroenterol Hepatol 2011;26:943-51.

132 Jepsen $\mathrm{P}$, Watson $\mathrm{H}$, Andersen PK, et al. Diabetes as a risk factor for hepatic encephalopathy in cirrhosis patients. J Hepatol 2015;63:1133-8.

133 Rikkers L, Jenko P, Rudman D, et al. Subclinical hepatic encephalopathy: detection, prevalence, and relationship to nitrogen metabolism. Gastroenterology 1978:75:462-9.

134 Romero-Gómez Met al. Subclinical hepatic encephalopathy predicts the development of overt hepatic encephalopathy. Am J Gastroenterol 2001;96:2718-23.

135 Amodio P, Marchetti P, Del Piccolo F, et al. Spectral versus visual EEG analysis in mild hepatic encephalopathy. Clin Neurophysiology 1999;110:1334-44.

136 Jackson CD, Gram M, Halliday E, et al. New spectral thresholds improve the utility of the electroencephalogram for the diagnosis of hepatic encephalopathy. Clin Neurophysiology 2016;127:2933-41.

137 Bajaj JS, Heuman DM, Sterling RK, et al. Validation of EncephalApp, smartphonebased Stroop test, for the diagnosis of covert hepatic encephalopathy. Clin Gastroenterology Hepatology 2015;13:1828-35.

138 Berlioux P, Robic MA, Poirson H, et al. Pre-transjugular intrahepatic portosystemic shunts (tips) prediction of post-TIPS overt hepatic encephalopathy: the critical flicker frequency is more accurate than psychometric tests. Hepatology 2014;59:622-9.

139 Mardini H, Saxby BK, Record CO. Computerized psychometric testing in minimal encephalopathy and modulation by nitrogen challenge and liver transplant. Gastroenterology 2008;135:1582-90.

140 Nardelli S, Gioia S, Pasquale C, et al. Cognitive impairment predicts the occurrence of hepatic encephalopathy after transjugular intrahepatic portosystemic shunt. Am J Gastroenterology 2016;111:523-8.

141 Vilstrup H, Amodio P, Bajaj J, et al. Hepatic encephalopathy in chronic liver disease: 2014 practice guideline by the American association for the study of liver diseases and the European association for the study of the liver. Hepatology 2014:60:715-35

142 Kochar N, Tripathi D, Ireland H, et al. Transjugular intrahepatic portosystemic stent shunt (TIPSS) modification in the management of post-TIPSS refractory hepatic encephalopathy. Gut 2006;55:1617-23. 
143 Wong F. Cirrhotic cardiomyopathy. Hepatol Int 2009;3:294-304.

144 Grose RD, Nolan J, Dillon JF, et al. Exercise-Induced left ventricular dysfunction in alcoholic and non-alcoholic cirrhosis. J Hepatol 1995;22:326-32.

145 Møller S, Lee SS. Cirrhotic cardiomyopathy. J Hepatol 2018;69:958-60.

146 Rabie RN, Cazzaniga M, Salerno F, et al. The use of E/A ratio as a predictor of outcome in cirrhotic patients treated with transjugular intrahepatic portosystemic shunt. Am J Gastroentero/ 2009;104:2458-66.

147 Cazzaniga M, Salerno F, Pagnozzi G, et al. Diastolic dysfunction is associated with poor survival in patients with cirrhosis with transjugular intrahepatic portosystemic shunt. Gut 2007;56:869-75.

148 Pudil R, Praus R, Hulek P, et al. Transjugular intrahepatic portosystemic shunt is associated with significant changes in mitral inflow parameters. Ann Hepatol 2013;12:464-70.

149 Billey C, Billet S, Robic MA, et al. A prospective study identifying predictive factors of cardiac decompensation after transjugular intrahepatic portosystemic shunt: the toulouse algorithm. Hepatology 2019;70:1928-41.

150 Shounak M, Vimal R, Colin S, et al. A retrospective analysis of the impact of diastolic dysfunction on one-year mortality after transjugular intrahepatic porto-systemic shunt, liver transplantation and non-transplant abdominal surgery in patients with cirrhosis. Ann Gastroenterol 2015;28:385-90.

151 Wannhoff A, Hippchen T, Weiss CS, et al. Cardiac volume overload and pulmonary hypertension in long-term follow-up of patients with a transjugular intrahepatic portosystemic shunt. Aliment Pharmacol Ther 2016;43:955-65.

152 Fili D, Falletta C, Luca A, et al. Circulatory response to volume expansion and transjugular intrahepatic portosystemic shunt in refractory ascites: relationship with diastolic dysfunction. Dig Liver Dis 2015;47:1052-8.

153 Modha K, Kapoor B, Lopez R, et al. Symptomatic heart failure after transjugular intrahepatic portosystemic shunt placement: incidence, outcomes, and predictors. Cardiovasc Intervent Radiol 2018;41:564-71.

154 Ruíz-del-Árbol L, Achécar L, Serradilla R, et al. Diastolic dysfunction is a predictor of poor outcomes in patients with cirrhosis, portal hypertension, and a normal creatinine. Hepatology 2013;58:1732-41.

155 Armstrong MJ, Gohar F, Dhaliwal A, et al. Diastolic dysfunction on echocardiography does not predict survival after transjugular intrahepatic portosystemic stent-shunt in patients with cirrhosis. Aliment Pharmacol Ther 2019;49:797-806.

156 Henriksen JHet al. Increased circulating pro-brain natriuretic peptide (proBNP) and brain natriuretic peptide (BNP) in patients with cirrhosis: relation to cardiovascular dysfunction and severity of disease. Gut 2003;52:1511-7.

157 Farias AQ, Silvestre OM, Garcia-Tsao G, et al. Serum B-type natriuretic peptide in the initial workup of patients with new onset ascites: a diagnostic accuracy study. Hepatology 2014;59:1043-51.

158 Choi J-H, Cho DK, Song Y-B, et al. Preoperative NT-proBNP and CRP predict perioperative major cardiovascular events in non-cardiac surgery. Heart 2010;96:56-62.

159 Cavasi A, Cavasi E, Grigorescu M, et al. Relationship between NT-proBNP and cardio-renal dysfunction in patients with advanced liver cirrhosis. J Gastrointestin Liver Dis 2014;23:51-6.

160 Zhao J, Li S, Ren L, et al. Pro-brain natriuretic peptide and troponin T-Hypersensitivity levels correlate with the severity of liver dysfunction in liver cirrhosis. Am J Med Sci 2017;354:131-9.

161 Jansen C, Schröder A, Schueler R, et al. Left ventricular longitudinal contractility predicts acute-on-chronic liver failure development and mortality after transjugular intrahepatic portosystemic shunt. Hepatol Commun 2019;3:340-7.

162 European Association for the Study of the Liver. EASL clinical practice guidelines on nutrition in chronic liver disease. J Hepatol 2019;70:172-93.

163 Nardelli S, Lattanzi B, Torrisi S, et al. Sarcopenia is risk factor for development of hepatic encephalopathy after transjugular intrahepatic portosystemic shunt placement. Clin Gastroenterology Hepatology 2017;15:934-6.

164 Benmassaoud A, Roccarina D, Yu D, et al. SAT-016-Impact of sarcopenia in patients undergoing transjugular intrahepatic portosystemic shunt insertion for refractory ascites. J Hepatol 2019;70:e632.

165 Cabrera J, Maynar M, Granados R, et al. Transjugular intrahepatic portosystemic shunt versus sclerotherapy in the elective treatment of variceal hemorrhage. Gastroenterology 1996;110:832-9.
166 Escorsell Aet al. Tips versus drug therapy in preventing variceal rebleeding in advanced cirrhosis: a randomized controlled trial. Hepatology 2002:35:385-92.

167 García-Villarreal L, Martínez-Lagares F, Sierra A, et al. Transjugular intrahepatic portosystemic shunt versus endoscopic sclerotherapy for the prevention of variceal rebleeding after recent variceal hemorrhage. Hepatology 1999;29:27-32.

168 Henderson JM, Boyer TD, Kutner MH, et al. Distal splenorenal shunt versus transjugular intrahepatic portal systematic shunt for variceal bleeding: a randomized trial. Gastroenterology 2006;130:1643-51.

169 Jalan R, Forrest EH, Stanley AJ, et al. A randomized trial comparing transjugular intrahepatic portosystemic stent-shunt with variceal band ligation in the prevention of rebleeding from esophageal varices. Hepatology 1997;26:1115-22.

170 Angermayr B, Cejna M, Karnel F, et al. Child-Pugh versus MELD score in predicting survival in patients undergoing transjugular intrahepatic portosystemic shunt. Gut 2003; 52:879-85

171 Ochs A, Rössle M, Haag K, et al. The transjugular intrahepatic portosystemic stentshunt procedure for refractory ascites. N Engl J Med 1995;332:1192-7.

172 Wong F, Sniderman K, Liu P, et al. The mechanism of the initial natriuresis after transjugular intrahepatic portosystemic shunt. Gastroenterology 1997;112:899-907.

173 Riggio 0, Angeloni S, Salvatori FM, et al. Incidence, natural history, and risk factors of hepatic encephalopathy after transjugular intrahepatic portosystemic shunt with polytetrafluoroethylene-covered stent grafts. Am J Gastroenterol 2008; 103:2738-46.

174 Haskal ZJ, Radhakrishnan J. Transjugular intrahepatic portosystemic shunts in hemodialysis-dependent patients and patients with advanced renal insufficiency: safety, caution, and encephalopathy. J Vasc Intervent Radiology 2008;19:516-20.

175 Dariushnia SR, Haskal ZJ, Midia M, et al. Quality improvement guidelines for transjugular intrahepatic portosystemic shunts. J Vasc Intervent Radiology 2016;27:1-7.

176 Weisbord SD, Gallagher M, Jneid H, et al. Outcomes after angiography with sodium bicarbonate and acetylcysteine. N Engl J Med 2018;378:603-14.

177 Venkatesan AM, Kundu S, Sacks D, et al. Practice guidelines for adult antibiotic prophylaxis during vascular and interventional radiology procedures. Written by the Standards of Practice Committee for the Society of Interventional Radiology and Endorsed by the Cardiovascular Interventional Radiological Society of Europe and Canadian Interventional Radiology Association [corrected]. J Vasc Interv Radiol 2010;21:1611-30. quiz 1631

178 Tavare AN, Wigham A, Hadjivassilou A, et al. Use of transabdominal ultrasoundguided transjugular portal vein puncture on radiation dose in transjugular intrahepatic portosystemic shunt formation. Diagn Interv Radiol 2017;23:206-10.

179 Perarnau JM, Le Gouge A, Nicolas C, et al. Covered vs. uncovered stents for transjugular intrahepatic portosystemic shunt: a randomized controlled trial. $J$ Hepatol 2014:60:962-8.

180 La Mura V, Abraldes JG, Berzigotti A, et al. Right atrial pressure is not adequate to calculate portal pressure gradient in cirrhosis: a clinical-hemodynamic correlation study. Hepatology 2010;51:2108-16.

181 Silva-Junior G, Turon F, Baiges A, et al. Timing affects measurement of portal pressure gradient after placement of transjugular intrahepatic portosystemic shunts in patients with portal hypertension. Gastroenterology 2017;152:1358-65.

182 Masson S, Mardini HA, Rose JD, et al. Hepatic encephalopathy after transjugular intrahepatic portosystemic shunt insertion: a decade of experience. QJM 2008; 101:493-501.

183 Shi Y, Tian X, Hu J, et al. Efficacy of transjugular intrahepatic portosystemic shunt with adjunctive embolotherapy with cyanoacrylate for esophageal variceal bleeding. Dig Dis Sci 2014;59:2325-32.

184 Xiao T, Chen L, Chen W, et al. Comparison of transjugular intrahepatic portosystemic shunt (tips) alone versus tips combined with embolotherapy in advanced cirrhosis. J Clin Gastroenterol 2011:45:643-50.

185 Lake D, Guimaraes M, Ackerman S, et al. Comparative results of Doppler sonography after tips using covered and bare stents. Am J Roentgenology 2006:186:1138-43.

186 Mah JM, DeWit Y, Djerboua M, et al. Association between institutional factors and long-term survival following transjugular intrahepatic portosystemic shunt. Hepatol Commun 2019:3:838-46.

187 Sarwar A, Zhou L, Novack V, et al. Hospital volume and mortality after transjugular intrahepatic portosystemic shunt creation in the United States. Hepatology 2018;67:690-9. 